\title{
Staatspräsident Eugen Bolz (1881 - 1945) - zum 70. Jahrestag seiner Hinrichtung (mit unveröffentlichten Quellen)
}

\author{
Von DOMINIK BURKard
}

I.

„Papst Leo XIII. verlangt, dass nur solche Männer als Abgeordnete aufgestellt und gewählt werden sollen, die sittlich intakt, religiös zuverlässig und bereit seien, in den die Religion und Moral berührenden Fragen des öffentlichen Lebens den Grundsätzen der christlichen Moral zu folgen. Wenn einer, so entsprach Bolz diesen Anforderungen. Er brachte zum Parlamentarier eine lautere Gesinnung, eine unaufdringliche, aber ehrliche und tiefe Überzeugung, und den besten Willen mit, dem Volke zu dienen, und es aus dem Wirrwarr herauszuführen, in den Krieg und Revolution es hineingestossen hatten "1.

Mit diesen Sätzen beginnt eine Würdigung, die der Breslauer Philosophieprofessor Ludwig Baur $(1871-1943)^{2}$, bis 1925 Mitglied des Württembergischen Land-

${ }^{1}$ Ludwig Baur, Eugen Bolz als württembergischer Landtagsabgeordneter (handschriftlich korrigiertes und von Baur unterschriebenes dreiseitiges Typoskript, datiert auf den 30. November 1931, offenkundig für die Presse bestimmt). HStAS Q 1/25 Bü 54.

${ }^{2}$ Gebürtig aus Dettingen bei Biberach, Studium der Philosophie und Theologie in Tübingen, 1895 Priesterweihe, Vikar in Schramberg, 1897 Repetent am Wilhelmsstift in Tübingen, Studien- und Forschungsreisen nach Rom, Paris, Oxford, Cambridge (später auch nach Spanien), 1903 a.o. Professor für Philosophie an der Katholisch-Theologischen Fakultät Tübingen, 1914-1916 Feldgeistlicher, dann Kriegsgefangenenseelsorger in Stuttgart, 1919 Promotion zum Dr. theol. h.c. in Tübingen, 1919/1920 Mitglied der württembergischen Verfassungsgebenden Versammlung, ab Dezember 1920 wieder Philosophieprofessor in Tübingen, zugleich 1920-1925 als Zentrumsabgeordneter Mitglied im Landtag, 1925 o. Professor für Philosophie in Breslau, 1936 emeritiert, Ruhestand in Starnberg. Zu ihm: Dominik Burkard, Theologie und Gesellschaft im Umbruch. Die Katholisch-Theologische Fakultät Tübingen in der Weimarer Republik, in: Rottenburger Jahrbuch für Kirchengeschichte 24 (2005) S. 51-85, hier S. 57, 61-64, 83 f.; Frank RABERG (Bearb.), Biographisches Handbuch der württembergischen Landtagsabgeordneten 1815-1933, bearb. im Auftrag der Kommission für geschichtliche Landeskunde in Baden-Württemberg, Stuttgart 2001, S. 33 f.; Dominik BurKard, Art. Baur, in: Württembergische Biographien 3 (im Druck). 
tags, seinem ehemaligen Fraktionsvorsitzenden Eugen Bolz $(1881-1945)^{3}$ zum 50. Geburtstag 1931 widmete. Und Baur fährt fort: „Bolz war überzeugter Monarchist gewesen und Offizier. Es fiel ihm, wie fast uns allen, nicht leicht, sich in die neue Lage innerlich hineinzufinden, zumal da die Revolution sehr üble Elemente an die Oberfläche gespült hatte, die sich nun anschickten, die Situation in ihrem Sinne auszugestalten und die ,res publica' zur ,res privata' zu machen. Aber Bolz war klug und klarblickend genug, um zu sehen, dass eine andere Möglichkeit gar nicht mehr bestand, als eine Neuorganisation des Landes zu erstreben auf dem Boden der republikanischen Verfassung, die nun zu gestalten war, zu gestalten mit dem Ziel, möglichst so viel an christlichen und gesunden konservativen Elementen in sie einzubauen, als es die ganz und gar ungünstigen Umstände gestatteten, die den Parteien der Linken die absolute Majorität in die Hand gespielt hatten [...]“.

Die Fraktion „präsentierte Bolz zum Justizminister und Graf, den unermüdlichen Arbeiter zum Innenminister. Was Bolz besonders auszeichnete war und ist jenes politische Fingerspitzengefühl, ohne das man weder ein politisches Amt, noch ein Mandat übernehmen sollte. Es war jenes Feingefühl für das, was Görres einmal in die geistvolle Prägung gebracht hat: ,Alle Stärke ist auf die Dauer bei der Mässigung, wie aller Erfolg bei der Billigkeit‘. [...] Die Führung des Justizministeriums durch Bolz zeichnete sich aus durch Klarheit und Sauberkeit und durch ein hohes Maß an Rechtlichkeit. [...] Es waren die Tage des Kappputsches, wo der Reichstag mit Fehrenbach nach Stuttgart floh. In den Daimlerfabriken brodelte es auch wie in einem Hexenkessel. In beiden Fällen griff man in Württemberg energisch zu und konnte so das Land von dem Seuchenherd abriegeln, der in Mitteldeutschland sass. Die Inflationsperiode machte der Regierung schwerste Sorgen [...]. Nach Grafs allzu frühem Tod übernahm Bolz das Innenministerium, und mit ihm einen neuen und sehr viel weiteren aber auch einflussreicheren Wirkungskreis. Er bekam die Polizei und die Staatsverwaltung in die Hand und damit die wesent-

$3 \mathrm{Zu}$ ihm nach wie vor unverzichtbar: Max Miller, Eugen Bolz - Staatsmann und Bekenner, Stuttgart 1951. - Es folgte einige Jahre später noch ein Lebensbild im Staatslexikon der Görresgesellschaft: Max Miller, Eugen Bolz, in: Staatslexikon ${ }^{6} 2$ (1958) Sp.116-118. Außerdem: August Hagen, Eugen Bolz 1881-1945, in: Ders., Gestalten aus dem schwäbischen Katholizismus, Bd.3, Stuttgart 1954, S.202-243; August Hagen, Geschichte der Diözese Rottenburg, Bd.3, Stuttgart 1960 (Register); Rudolf Morsey, Eugen Bolz (1881-1945), in: Jürgen AreTz/Rudolf Morsey/Anton Rauscher (Hg.), Zeitgeschichte in Lebensbildern, Bd.5, Mainz 1985, S. 88-103; Joachim KöHLER, Eugen Bolz (1881-1945). Politiker aus Leidenschaft. Zum 100. Geburtstag des württembergischen Ministers und Staatspräsidenten, in: Rottenburger Jahrbuch für Kirchengeschichte 1 (1982) S. 21 - 32; Joachim Köhler (Hg.), Christentum und Politik. Dokumente des Widerstands. Zum 40. Jahrestag der Hinrichtung des Zentrumspolitikers und Staatspräsidenten Eugen Bolz am 23. Januar 1945, Sigmaringen 1985; Joachim SAILER, Eugen Bolz und die Krise des politischen Katholizismus in der Weimarer Republik, Tübingen 1994; Frank RaberG, Eugen Bolz. Zwischen Pflicht und Widerstand (Prägende Köpfe aus dem Südwesten, Bd.3), Leinfelden-Echterdingen 2009. 
lichen Machtmittel des Staates. Bei der Einstellung der Sozialisten und Kommunisten zu Justiz und Polizei war Bolz naturgemäss das beliebte Angriffsziel dieser Kreise. Die stramme Handhabung der Schwenninger Unruhen schuf auf lange Zeit hinaus wieder Ruhe im Lande" .

Angesichts des Letzteren fällt ins Gewicht, wenn der Sozialdemokrat Wilhelm Keil (1870-1968) $)^{5}$, ein langjähriger, scharfer politischer Gegner, ebenfalls 1931 in seinem Glückwunschschreiben an Bolz bekannte: „Gerade die Tatsache, daß ich in vielen Einzelfragen des politischen Tageskampfes andere Anschauungen vertreten habe als die Ihrigen, gibt mir Anlaß, rückhaltlos anzuerkennen, daß Sie sich stets nur von der lautersten Absicht, dem Wohl des Volks- und Staatsganzen zu dienen, haben leiten lassen. Ich beglückwünsche Sie daher aufs herzlichste zu den Erfolgen Ihres dem Gemeinwohl dienenden Wirkens"6.

Worauf diese Achtung über die Parteigrenzen hinaus beruhte, brachte ein Mitglied der Landtagsfraktion des Zentrums, Studienrat Aloys Küchle (1888-1936) zum Ausdruck: „Bewundernswert ist gar oft die Ruhe, mit der Staatspräsident Dr. Bolz andere Meinungen anhört. Er nimmt jeden Vorschlag, mag er kommen, woher er will, gerne an, wenn er brauchbar ist. Freilich zeigt er bisweilen auch eine Entschiedenheit in der Vertretung seiner Meinung, die sich, wenn auch selten, bis zur explosiven Entladung entwickeln kann, namentlich wenn er eine von ihm als richtig erkannte Überzeugung durchsetzen will. In kleinen Dingen ist er stets milde und nachsichtig, manchmal auch in größeren. [...] Wenn er vielleicht manchmal ohne parteitaktische Rücksichten auch Fehler zugibt, die gemacht wurden, oder auf übertriebene Forderungen einzelner Stände die richtige Antwort zu finden weiß, die zwar nicht immer verheißungsvoll klingt, so unterscheidet sich der

${ }^{4}$ BAur, Eugen Bolz (wie Anm. 1).

${ }^{5}$ Gebürtig aus Helsa/Kassel, evangelisch, 1884-1887 Drechslerlehre in Kassel, bis 1893 als Drechsler tätig, 1887 Mitglied der SPD, 1894-1896 Angestellter der Mannheimer Ortskrankenkasse, 1896-1911 und 1923-1930 Redakteur bei der „Schwäbischen Tagwacht“ in Stuttgart, seit 1902 Leiter des politischen Teils, 1911-1921 Schriftsteller und Zigarrenhändler in Ludwigsburg, 1919/1920 Mitglied und Präsident der Verfassungsgebenden Landesversammlung, 1920-1933 Mitglied des württembergischen Landtags, 1920-1932 auch Mitglied des Reichstags, 1921-1923 Staatsminister des Ministeriums für Arbeit und Ernährung, 1933 Streichung der Ministerpension, wiederholte Hausdurchsuchungen und Beschlagnahme von Büchern, 1945 Leiter der Kommunalvertretung in Ludwigsburg, Juni bis November 1945 Präsident der Landrätekonferenzen in Württemberg-Baden, 1945-1955 Vorsitzender des Aufsichtsrats der Bausparkasse Wüstenrot (Ludwigsburg), 1946-1952 Mitglied des Landtags von Württemberg-Baden. Zu ihm: Raberg, Biographisches Handbuch (wie Anm. 2) S. 425-427.

${ }^{6}$ Zit. nach Miller, Eugen Bolz (wie Anm.3) S. 400.

7 Gebürtig aus Zimmern unter der Burg/Rottweil, katholisch, Studium in Tübingen, Oberpräzeptor, später Studienrat in Geislingen-Altenstadt, 1926 Studienrat in Ulm, Mitglied der Zentrumspartei, 1928 Vorstandsmitglied des Landesverbandes Württemberg der paneuropäischen Union, 1920-1933 Mitglied des württembergischen Landtags. Zu ihm: RABERG, Biographisches Handbuch (wie Anm. 2) S. $482 \mathrm{f}$. 
Zentrumsführer als Politiker von den Leuten mit demagogischen Allüren so deutlich und vorteilhaft, daß man auch außerhalb unserer Partei das zu schätzen weiß. Da finden wir dann keine Schönrednerei, keine taktische Anpassung an die Wünsche der Zuhörer, sondern offene Darlegung der Verhältnisse“" seine Politik orientierte, an der katholischen Soziallehre und Moral, habe er - so Küchle - in seinen programmatischen Wahlreden, bei Versammlungen und auch als Redner auf Katholikentagen, immer wieder deutlich gemacht.

Das Bekenntnis zu einer christlich orientierten Politik ist das eine; Sonntagsreden, so könnte man sagen. Etwas anderes ist das intime, nicht für die Öffentlichkeit bestimmte innere Erleben und Empfinden. Zumal nicht an Sonn- und Festtagen, sondern im grauen Alltag oder in den düsteren Stunden des Lebens. Bei Bolz stimmte beides zusammen - Bekenntnis, Politik und inneres Fühlen. Richtschnur seines Handelns blieb sein durch das persönliche Bemühen um kontinuierliche Gewissens- und Glaubensbildung geschärftes Gefühl der Verantwortung gegenüber einem „Unverfügbaren“, „Objektiven“: Gott.

\section{II.}

1922 war eine erste nationalsozialistische Welle über Württemberg hinweggegangen, 1924 waren drei Vertreter des „Völkisch-sozialen Blocks“ in den Landtag gewählt worden. Martin Ulmer stellte jüngst fest, dass „das Treiben der völkischen und nationalsozialistischen Szene in Stuttgart und Württemberg" von der Polizeiführung toleriert wurde. Während die Polizeiführung jede tatsächliche oder vermeintliche Straftat der KPD verfolgen ließ, ging sie etwa gegen die Judenhetze der NSDAP nicht vor. Verantwortlich dafür war Polizeipräsident Rudolf Klaiber (1873-1957) $)^{9}$. Als die SPD im Juni 1931 einen Untersuchungsausschuss des Landtags zur Aufklärung von Verbindungen der Polizei zur NSDAP forderte, dementierte Klaiber in einem Schreiben an das Innenministerium die Vorwürfe. Der Untersuchungsausschuss wurde eingerichtet, mit dem Ende der Legislaturperiode

8 15. Dezember 1931 Küchle, Ulm, an Bolz. HStAS Q 1/25 Bü 54.

9 Gebürtig aus Künzelsau, evangelisch, 1891 Studium der Rechtswissenschaften in Tübingen und Berlin, Staatsprüfungen 1895 und 1897, 1896 Regierungsreferendar und Assessor bei württembergischen Oberämtern, 1899 Heirat, 1910-1923 Dozent für öffentliches Recht an der TH Stuttgart, 1911 Oberamtmann der Stadtdirektion Stuttgart und Stellvertreter des Stadtdirektors, dort Leiter der nachrichtendienstlichen Abwehrstelle, im Ersten Weltkrieg Leiter der militärischen Zentralpolizeistelle Württemberg, 1914-1922 Leiter des Württembergischen Landespolizeiamts, 1920 Ernennung zum Oberregierungsrat, 1923 1938 Polizeipräsident in Stuttgart und Leiter des Württembergischen Landeskriminalpolizeiamts, 1931-1935 auch Preisüberwachungskommissar für Württemberg. Zu ihm: http:// www.leo-bw.de/web/guest/detail/-/Detail/details/PERSON/kgl_biographien/129435260/ Klaiber+Rudolf (abgerufen am 23.10.2015). 
im Frühjahr 1932 aber eingestellt. In diesem Zusammenhang wird von Ulmer gegen die republikanische Regierung der Vorwurf erhoben, „durch Nichteingreifen und Hinnahme der massiven Agitation und der Straftaten der völkischen Szene und der NSDAP“s seit 1922 zum Aufstieg der NSDAP beigetragen zu haben ${ }^{10}$.

Bolz war allerdings von Anfang an nicht nur klar, dass die Bewegung aus weltanschaulichen Gründen abzulehnen war, vielmehr war er auch von ihrer Gefährlichkeit überzeugt. So sagte er etwa auf einer Zentrumsversammlung in Ehingen im Oktober 1923: „Wir in Württemberg haben diese nationalsozialistische Bewegung von Anfang an unterdrückt; in dieser Beziehung mache ich keinen Unterschied zwischen den Nationalsozialisten und den Linksorganisationen. Unsere Parteiangehörigen und das ganze katholische Volk möchte ich vor dem Nationalsozialismus eindringlich warnen. Derselbe ist rein heidnisch und eine Zusammenarbeit mit diesem ist nicht möglich"11.

Ende 1929 setzte erneut ein scharfer politischer Kampf ein, der sich in den nächsten Jahren noch steigerte. Aufmärsche und Versammlungen, Verleumdungen, Hetzkampagnen, Saalschlachten und anderes mehr beherrschten die Szene. Manche Parteien wurden durch paramilitärische Vereinigungen unterstützt - ein hohes Gefahrenpotential für Bolz, der nicht nur das Amt des Ministerpräsidenten innehatte, sondern auch das Innenministerium leitete. Die Zentrumspartei mit Bolz in der vordersten Reihe mobilisierte ihre Anhänger und versuchte in zahllosen Versammlungen und Reden den Radikalisierungen entgegenzutreten. Auch im Reichstag und im Landtag sparte Bolz nicht mit Kritik am Nationalsozialismus bzw. mit Warnungen vor dessen politischer Etablierung ${ }^{12}$. Nur einige wenige Beispiele: Auf dem Zentrumsparteitag am 24. März 1930 sagte Bolz: „Die Frage nach der Arbeitsfähigkeit des Parlaments und der Parteien ist eine unmittelbar gegenwärtige und praktische, die jetzt und in den nächsten Jahren zur Entscheidung steht. Sind die Parteien dazu nicht imstande, versagt das Parlament, dann bleibt freilich nur die Möglichkeit, die bei uns immer als letzte an die Wand gemalt wird: Die Diktatur! Bewahre uns das Schicksal davor! "13 Ähnlich, wenn auch wesentlicher bestimmter, nach den Wahlerfolgen im September 1930 in Friedrichshafen: „Wir haben [...] heute zwei radikale Parteibewegungen, die eine rechts, die andere links. [...] Die Kommunisten kennt jeder. [...] Sie haben seit Jahren offen [...] für die Revolution Propaganda gemacht. [...] Hier wissen wir, daß wir eine revolutionäre Partei vor uns haben. Viel schwerer ist es für den einzelnen, einen Blick in die nationalsozia-

10 Vgl. Martin Ulmer, Der Stuttgarter Polizeipräsident Rudolf Klaiber und sein Verhältnis zur völkischen Bewegung und zur NSDAP bis 1933. http://hotel-silber.de/wp-content/ uploads/2015/02/RollevonPolizeichefRudolfKlaiberbis1933_Dr.MartinUlmer.pdf (abgerufen am 15.10.2015).

11 Zit. nach SaIler, Eugen Bolz (wie Anm.3) S.64f.

12 Vgl. Hagen, Geschichte (wie Anm. 3) 81 f.; Miller, Eugen Bolz (wie Anm.3) S.384f., 390.

13 Zit. nach KöHLER, Eugen Bolz (1881-1945) (wie Anm.3) S. 29. 
listische Partei zu tun und darüber klar zu werden, was diese Partei eigentlich will. [...] Zunächst kritisiert sie, klagt an und verspricht. [...] Man weiß gar nicht recht, ist die nationalsozialistische Partei eine legale oder eine revolutionäre Partei. [...] Was der Sieg des Kommunismus bedeutet, weiß jeder; er bedeutet Revolution. Der Sieg des Nationalsozialismus [...] bedeutet die Diktatur. Und eine solche Diktatur wäre die Revolution"14.

1932 stand Bolz auf dem Höhepunkt seines Schaffens. Das Land Württemberg fand damals im Reich überall durch seine wirtschaftliche Solidität Anerkennung, und auch Bolz hatte sich durch seinen Weitblick und seine Gerechtigkeit - oder "Sachlichkeit"15, wie er es nannte -, große Beliebtheit erworben; und das trotz seiner klaren konfessionell-religiösen Ausrichtung und das in einem zu zwei Dritteln protestantischen Land ${ }^{16}$.

Seit 1932 spitzte sich die gesamtpolitische Lage, befeuert durch die schwere Wirtschaftskrise, aber noch einmal zu. Auch in Württemberg wurden die politischen Parolen immer schriller, mitunter auch verlogener. Am heftigsten waren wohl die Vorwürfe, die der zwar zahlenmäßig kleine, aber doch sehr aktive „Nationalsozialistische Evangelische Pfarrerbund“ in einem Wahlaufruf gegen Bolz und das Zentrum schleuderte: „Es dürfte Ihnen nicht unbekannt sein, daß das Zentrum im Verein mit dem antichristlichen Marxismus den Protestantismus und die reformatorischen Glaubens- und Lebensgüter unseres Volkes zu vernichten beabsichtigt [...]. Es ist erwiesen, daß der Zentrumskatholizismus mit dem Bolschewismus im Bunde steht, um durch den Bolschewismus den Protestantismus vernichten zu lassen und dadurch die Voraussetzungen zu schaffen, in Deutschland die Alleinherrschaft der Katholischen Kirche aufzurichten [...]. Auch für Württemberg droht die Diktatur Bolz unter freundlicher Unterstützung der Sozialdemokratie, wenn die Nationalsozialisten nicht derart stark in den Landtag einziehen, daß das Zentrum zu einer Schwenkung in seiner Politik gezwungen wird. Wir würden dann noch Schlimmeres erleben, als wir bereits unter der Regierung Bolz, die eine reine Zentrumsregierung war, in der die Deutschnationalen wenig oder gar nichts zu sagen hatten, erleben mußten“"17.

Bolz selbst wies immer wieder auf die Gefahren hin, die von der nationalsozialistischen Agitation für die Außen- und Wirtschaftspolitik Deutschlands ausgingen. Am 24. Februar 1932 hielt er im Reichstag eine Rede, die an schneidender Klarheit und Schärfe, gleichzeitig aber auch an Gerechtigkeit, wohl kaum zu überbieten war. Sie wurde - wie das Protokoll zeigt - von den Nationalsozialisten

14 Zit. nach SAILER, Eugen Bolz (wie Anm.3) S. 90.

15 Vgl. auch Hagen, Eugen Bolz (wie Anm.3) S.233f.

16 Dass ein Katholik württembergischer Staatspräsident geworden war, hatte 1929 in der sozialistischen und demokratischen Presse zu starken Vorwürfen gegen die v. a. von evangelischer Seite gestützten Rechtsparteien geführt, die Bolz das Amt angetragen hatten. Vgl. Miller, Eugen Bolz (wie Anm.3) S.336.

17 Zit. nach Miller, Eugen Bolz (wie Anm.3) S. 409. 
vielfach durch Zwischenrufe unterbrochen, vom Zentrum (und teilweise auch von der Sozialdemokratie) mit starkem Beifall bedacht. In dieser Rede führte Bolz gegenüber dem Nationalsozialismus u. a. aus: „Wir bestreiten der Opposition nicht das Recht zur Kritik, aber jede Kritik hat ihre Grenze. Sie hat ihre Grenze da, wo die nationalen Interessen geschädigt werden. (Sehr richtig!) Jede Kritik hat auch eine Aufgabe: die Aufgabe, den Weg zur Besserung zu zeigen. Ihre Kritik, meine Herren Nationalsozialisten, ist grenzenlos, maßlos, rein negativ, ohne Inhalt. (Laute Zustimmung im Zentrum und bei den Sozialdemokraten.) Ihre Kritik ist nichts als Verhetzung, Vergiftung, Zerstörung und Zersetzung, während die Aufgaben der Politik in ihrer ganzen Größe und Schwere gelöst werden wollen. [...] Die Herbeiführung der Arbeitsunfähigkeit des Parlaments, die reine Negation, das scheint der Inhalt des neuen Systems zu sein. (Sehr richtig! In der Mitte.) [...] Das Zentrum ist seiner ganzen Vergangenheit und inneren Einstellung nach zur Zusammenarbeit mit jeder Partei bereit, die auf dem Boden der Verfassung aufbauende Arbeit leisten will. (Sehr wahr! Im Zentrum.) Wollen das die Nationalsozialisten? (Zuruf von den Nationalsozialisten: Nein! - Lachen im Zentrum und Zurufe: Wo ist Groener?) Wollen Sie eine Partei in diesem Sinne sein, wollen Sie ernsthaft eine Zusammenarbeit, oder wollen Sie nur zur Macht kommen, um die Diktatur vorzubereiten und zu übernehmen? Welches sind Ihre Absichten, politisch, wirtschaftlich, kulturell? Ihr Programm ist zwar nach dem Gedanken der Verfasser ewig und unabänderlich, aber es ist widerspruchsvoll und mystisch ${ }^{18}$. ,Was kümmern uns politische Tagesfragen!‘ sagen ihre Führer. Sie wollen zur Macht und hoffen, daß dann die Millionen befriedigt aufschreien, wie es für die Kandidatenaufstellung der Nationalsozialisten prophezeit worden ist. Einen so geheimnisvollen und dunklen Weg lehnt das Zentrum ab. (Sehr wahr! Im Zentrum.) Stürzen Sie (zu den Nationalsozialisten) die Regierung, das Zentrum wird bei der anderen Partie nicht dabei sein. [...] Noch ein Wort zu unseren innenpolitischen Kämpfen. So schwer der Druck und die Not auf unserem Volke lasten, sie werden noch verschärft durch die politische Agitation. Von zwei Seiten wird das Volk systematisch verhetzt und vergiftet. (Zurufe von den Nationalsozialisten.) Kinder werden organisiert. In den Schulen wird politisiert, und diese Politisierung wächst mit der Höhe der Schulen, bis sie schließlich auf der Universität zur Reife geführt wird. Der Ton in den Versammlungen und in der Presse übersteigt alles bisher Dagewesene. (Sehr wahr! Im Zentrum.) Schlägereien, Stechereien, Schießereien sind an der Tagesordnung. Kampfbereite Organisationen werden von den Parteien aufgezogen, und damit ein Punkt in dieser Verhetzung und Vergiftung nicht fehle, wird auch das konfessionelle Moment wieder hervorgeholt. [...] Von Tag zu Tag wächst die Leidenschaft. Wie lange soll das noch gehen? Es reift die Zeit heran,

${ }^{18} \mathrm{Vgl}$. auch die offizielle Anfrage des Zentrums an die Reichstagsfraktion der NSDAP vom 31. Januar 1933. Abgedruckt bei Hubert Gruber (Hg.), Katholische Kirche und Nationalsozialismus 1930-1945. Ein Bericht in Quellen, Paderborn 2006, S. 16 f. 
wo der Staat mit anderen und mit schärferen Mitteln wird zugreifen müssen, und zwar mit Mitteln, die Sie (nach rechts) anwenden würden, wenn Sie zur Macht gelangen würden. (Sehr gut! Im Zentrum. - Zuruf von den Nationalsozialisten: Wir sind doch keine Vertreter der Demokratie!) - Nein, Sie sind Vertreter der Diktatur. Sie bestätigen das. Darum wollen wir den Weg nicht mit Ihnen gemeinsam gehen"19.

Auf dem Ulmer Parteitag des Zentrums im März 1932 bezeichnete Bolz den Nationalsozialismus als die in der momentanen Situation noch vor dem Kommunismus stehende Gefahr. Ihm habe der ganze Kampf zu gelten, hier gebe es kein Paktieren, denn die Nationalsozialisten wollten keine ruhige Arbeit, sondern nur die Diktatur ${ }^{20}$. Nach der Landtagswahl zog die NSDAP als größte Partei in den Landtag $\operatorname{ein}^{21}$. Da die von NSDAP und bürgerlichen Parteien geplante „katholikenreine Regierung“ jedoch nicht zustande kam, blieb die Regierung Bolz geschäftsführend im Amt. Die damals in der Presse auftauchende Meldung, bei der Bildung einer evangelischen Koalition in Württemberg von Deutschnationalen, Nationalsozialisten und Demokraten unter Ausschluss des Zentrums sei Polizeipräsident Klaiber als Staatspräsident und Innenminister vorgesehen ${ }^{22}$, dürfte Bolz nicht kaltgelassen haben.

Auch bei der Reichstagswahl im Juli 1932 siegten die Nationalsozialisten; es entstand eine ausweglose Situation, so dass es - auf Reichsebene - sogar zu Verhandlungen der Zentrumspartei und der BVP mit der NSDAP kam. An ihnen war zeitweilig auch Bolz beteiligt. Sein dabei gewonnener Eindruck von Hitler war wie er seiner Frau anvertraute - „ein besserer“, als er erwartet hatte ${ }^{23}$. Da der Reichstag im September erneut aufgelöst wurde, wurden auch diese Verhandlungen, die ohnehin der Überzeugung von Bolz widersprachen, abgebrochen ${ }^{24}$.

19 Protokoll der 58. Reichstagssitzung der 5. Wahlperiode vom 24. Februar 1932. Vgl. http://www.reichstagsprotokolle.de.

${ }^{20}$ Miller, Eugen Bolz (wie Anm. 3) S. 406.

21 NSDAP 26,4\%, Zentrum 20,5\%, SPD 16,6\%, Bauern- und Weingärtnerbund 10,7 \%, KPD 9,4 \%, Deutsche Staatspartei 4,8 \%, DNVP 4,3\%, CSVD 4,2 \%.

22 So am 11. Mai 1932 die „Schwäbische Tagwacht“ unter Berufung auf den sozialdemokratischen Pressedienst Berlin. Vgl. Ulmer, Der Stuttgarter Polizeipräsident (wie Anm. 10).

23 31. August 1932 Bolz, Berlin, an Maria Bolz. Zit. nach Miller, Eugen Bolz (wie Anm.3) S. 425.

24 Über das Motiv der Verhandlungsbereitschaft mit den Nationalsozialisten erklärte Bolz im November 1932 auf einer Kundgebung in Günzburg: „Ich [...] selbst habe gegen den Nationalsozialismus den Kampf mit allem Nachdruck geführt. Aber so gut wir mit den Sozialdemokraten zusammengearbeitet haben - nicht aus Gesinnungsgemeinschaft, sondern um die Masse der Arbeiter nicht in die fruchtlose Opposition zu drängen -, ebenso können wir uns eine Zusammenarbeit mit den Nationalsozialisten denken. [...] Man kann eine Millionenbewegung auf die Dauer nicht beiseiteschieben“. Zit. nach SAILER, Eugen Bolz (wie Anm. 3) S. 96. Ähnlich noch öfter. Vgl. ebd., S. 97. 
Noch im Januar 1933 gab Bolz seinem Parteifreund Heinrich Brüning $(1885-1970)^{25}$ das Wort, für die Ideen des Zentrums und damit gegen den Nationalsozialismus zu kämpfen. In Berlin und in Württemberg warnte er vor Hitler, der inzwischen Reichskanzler geworden war, vor Hugenberg und dem „preuBisch-militärischen Geist von Potsdam“26. Auf dem Ulmer Parteitag des Zentrums am 12. Februar 1933 ging Bolz mit den Nationalsozialisten und der Reichsregierung hart ins Gericht, bezeichnete die erneute Auflösung des Reichstags, die bevorstehenden Neuwahlen und in diesem Zusammenhang die erneute Aufputschung der Massen als völlig unnötig, beklagte die Ausgrenzung des Zentrums (als mäßigender Faktor) und wies den Vorwurf der Standpunktlosigkeit zurück: „Trotz der Zusammenarbeit mit den Sozialdemokraten in den letzten Jahren [im Reich] haben wir die grundsätzlichen Gegensätze in der Weltanschauung, in der Wirtschaftsauffassung nicht vergessen, wenn wir auch zusammen versuchten, praktische Arbeit für unser Volk zu leisten. Der innere Gegensatz ist geblieben. Wir wollen nicht Kampfgenossen der Marxisten sein, so wenig wir Kampfgenossen Hitlers und Hugenbergs sein wollen. Wir kämpfen nach beiden Seiten und betonen unsere Selbständigkeit, unsere einzigartige Bedeutung als katholische Volksgruppe“. Klarsichtig erkannte Bolz die große Gefahr, die mit einer Stärkung des Nationalsozialismus in den Märzwahlen kommen würde: „Man sucht ein neues Staatsrecht.

${ }^{25}$ Heinrich Brüning 1885-1970, gebürtig aus Münster, katholisch, Jurastudium in München, 1906 Studium der Philosophie, Geschichtswissenschaften, Germanistik und Staatswissenschaften in Straßburg, 1911 Staatsprüfung für das höhere Lehramt, danach zum Studium der Nationalökonomie in England, 1913 Wechsel nach Bonn, 1915 Promotion über „Die finanzielle, wirtschaftliche und gesetzliche Lage der englischen Eisenbahn unter Berücksichtigung der Frage ihrer Verstaatlichung“, 1915 Teilnahme am Ersten Weltkrieg, 1917 Maschinengewehrscharfschütze, 1919 Mitarbeiter des katholischen Sozialpolitikers Carl Sonnenschein in Berlin, dann Referent des preußischen Wohlfahrtsministers Adam Stegerwald, der auch den Deutschen Gewerkschaftsbund leitete, 1920 Geschäftsführer des Deutschen Gewerkschaftsbundes, 1924 Mitglied des Reichstags und finanzpolitischer Sprecher der Zentrumsfraktion, 1928-1929 auch Mitglied des preußischen Landtags, 1929 Vorsitzender der Zentrumsfraktion im Reichstag, 1930 von Hindenburg mit der Bildung eines neuen Kabinetts beauftragt und Reichskanzler, gezwungen, vor allem durch Notverordnungen zu regieren, sein Versuch, die Alliierten zur Beendigung der Reparationszahlungen zu bewegen, scheiterte, 1932 erzwungener Rücktritt, danach Rückzug in das katholische St. Hedwig Krankenhaus, nach der Verabschiedung des Ermächtigungsgesetzes im Untergrund, am 5. Juli 1933 löste er als Vorsitzender der Zentrumspartei das Zentrum auf, um einem Verbot durch die Nationalsozialisten zuvorzukommen, im Mai 1934 Flucht über Holland ins Exil, Großbritannien und die Schweiz in die USA, 1937 Lehrauftrag in Harvard, 1939 ordentliche Professur für Verwaltungswissenschaft, 1951-1953 Professor für politische Wissenschaften an der Universität Köln, 1955 Rückkehr in die USA. Zu ihm: Herbert KöNIG, Brüning. Kanzler in der Krise der Republik, Paderborn 2000; Herbert KöNIG, Brüning. Politiker ohne Auftrag, Paderborn 2005; Rudolph Morsey, Entstehung, Authentizität und Kritik von Brünings „Memoiren 1918-1934“ (Rheinisch-Westfälische Akademie der Wissenschaften, Reihe G, Bd. 202), Opladen 1975.

${ }^{26}$ Miller, Eugen Bolz (wie Anm.3) S. 434. 
Man formuliert einen neuen Begriff vom Staat, der sagt: Der Staat kann alles und darf alles; der einzelne ist nichts und bedeutet nichts. Wie Katholiken sich an einer solchen Staatsauffassung beteiligen können,“ - dies richtete sich gegen Papen - „ist mir unverständlich ${ }^{27}$, denn die letzte Konsequenz ist die, daß auch in religiöser Beziehung keine Freiheiten mehr bestehen. Deshalb wollen wir von allem Anfang an gegen diesen Begriff des Staates und diese Übersteigerung der staatlichen Macht Front machen. [...] Was wir fürchten von der jetzigen Regierung, und namentlich auch von Hugenberg, wollen wir offen aussprechen. Wir haben das Gefühl, daß in dieser neuen Regierung der Geist von Potsdam, der preußisch-militärische Geist wieder lebendig geworden ist. [...] Das ist der Geist, der den Krieg bis zum Weißbluten geführt hat und der uns in die fürchterliche Niederlage hineingeführt hat ${ }^{\text {"28. }}$. Deshalb wehrte sich Bolz gegen die „Ausschaltung des Katholizismus“, gegen die Minimierung seines Einflusses, und stellte klar: „Das ist keine Futterkrippenpolitik! [...] Wir wollen dabei sein, nicht aus Eigennutz, sondern einzig und allein, [...] weil wir nicht daran glauben, daß der politische Radikalismus rechts und links jemals das Volk dem inneren Frieden und dem entgegenführen wird, was der Reichskanzler Hitler am Schluß seiner Rundfunkrede genannt hat: einen Staat der Gerechtigkeit und der Volkswohlfahrt [...]. Wir kämpfen dafür, daß man den politischen Katholizismus braucht und nicht an die Wand drücken kann“29.

Als Hitler wenige Tage später nach Stuttgart kam und den Stuttgarter Schlosshof für seine zentrale Wahlkundgebung okkupieren wollte, wurde ihm dieser von Bolz verweigert. Hitler musste sich mit der Stadthalle begnügen. Aufgrund einer technischen Störung konnte seine Rede nicht in voller Länge ausgestrahlt werden, was seine Wut noch steigerte. Wieder bezichtigte er Bolz des Zusammengehens mit dem Marxismus und rief aus: „Herr Staatspräsident Bolz! Mit Ihnen rechne ich noch ab! “30 Die Rede offenbarte die Strategie Hitlers, wie sie in den kommenden Jahren typisch werden sollte, wenn er mithilfe des konstruierten Vorwurfs des Paktierens mit dem Marxismus die Tatsachen verdrehte und zu einem besonders

27 Bolz sprach damit aus, was wenig später auch Alois Hudal meinte, wenn er als Konsultor des Sanctum Officium die nationalsozialistische Weltanschauung auf die drei „Grundhäresien“ Rassenideologie, übertriebener Nationalismus und Staatstotalität zurückführte. Vgl. Dominik Burkard, Häresie und Mythus des 20. Jahrhunderts. Rosenbergs nationalsozialistische Weltanschauung vor dem Tribunal der Römischen Inquisition (Römische Inquisition und Indexkongregation, Bd. 5), Paderborn u. a. 2005, etwa S. 98-100.

28 Art. „Auseinandersetzung mit Papen. Eine bedeutsame Rede des Präsidenten Bolz“, in: Augsburger Postzeitung, 14. Februar 1933. Ein Exemplar in HStAS Q 1/25 Bü 22. Allerdings glaubte Bolz damals, Hitler noch zähmen zu können, während er in Hugenberg den gefährlicheren Gegner sah.

${ }^{29}$ So ebenfalls in der Ulmer Rede, zit. nach SAILER, Eugen Bolz (wie Anm.3) S.100f.

30 „Kurze Hinweise über den Charakter und Lebensweg von Eugen Bolz“ (undatiertes, dreiseitiges maschinenschriftliches Typoskript, ohne Verfasserangabe). HStAS Q 1/25 Bü 25. 
infamen Vorwurf nutzte, der bei Rechtskatholiken (und auch in Rom) allerdings durchaus auf Zustimmung gestoßen sein dürfte: „Nun sagt Staatspräsident Bolz, das Christentum und der katholische Glaube werde durch uns bedroht. Auch hier werden wir ehrlich handeln. Ich rede nicht nur vom Christentum, nein, ich bekenne auch, daß ich mich niemals mit ihnen verbinden werde, mit den Parteien der Zerstörung des Christentums. Wenn manche heute das bedrohte Christentum in Schutz nehmen wollen, wo war für sie das Christentum in diesen 14 Jahren, da sie mit dem Atheismus Arm in Arm gingen? Nein, dem Christentum ist niemals und zu keiner Zeit ein größerer innerer Bruch zugefügt worden, als in diesen $14 \mathrm{Jahren}$, da diese theoretisch christliche Partei mit den Gottesleugnern in einer Regierung saß. Bereits am 14. September 1930 war eine andere Möglichkeit klar gegeben. Aber nein, man konnte und wollte sich nicht von der Parteiwelt des Atheismus loslösen. Wir wollen unsere Kultur wieder mit christlichem Geist erfüllen, nicht nur in der Theorie. Nein, ausbrennen wollen wir die Fäulnis - Erscheinungen unserer Theater, unserer Literatur, ausbrennen dieses ganze Gift, das in diesen 14 Jahren in unser Leben hineingeflossen ist“31.

Den Vorwurf gegen Bolz, die Linken „umarmt“ zu haben, konterte Justizminister Joseph Beyerle (1881-1963)32 bei einer Wahlrede. Seit 1925 sei in Württemberg ununterbrochen mit den Rechtsparteien regiert worden; Bolz selbst sei vor Jahren fast Opfer eines bolschewistischen Attentats geworden: „Man sollte auf der Gegenseite mit diesem Vorwurf [ein „Novemberling“ zu sein] gerade deshalb zurückhaltend sein, weil der Mann, der jenes Attentat auf Dr. Bolz vorbereitet hatte, und der damals als Führer der deutschen Tscheka verurteilt wurde, heute bei den Na-

31 Art. „Die Reichskanzlerrede in Stuttgart“, in: Wolff's Telegraphisches Büro, Nr.323, 16. Februar 1933. Ein Exemplar in HStAS Q 1/25 Bü 22.

32 Gebürtig aus Hohenstadt/Aalen, katholisch, 1900-1904 Studium der Rechts- und Staatswissenschaften in Tübingen und Berlin, Gerichtsreferendar am Amtsgericht Heidenheim, 1906-1907 beim Landgericht und bei der Staatsanwaltschaft Ellwangen, 1907-1908 in einer Anwaltskanzlei in Stuttgart, 1908 Rechtsanwalt beim Landgericht Stuttgart, 1910 Gerichtsassessor beim Landgericht Tübingen, 1910-1911 beim Grundbuchamt Ulm, 1913 Justizministerialsekretär, 1918 Eintritt in die Zentrumspartei, 1919 Landesvorsitzender des Zentrums, seit 1920 Mitglied des engeren Reichsparteivorstands des Zentrums, 1921 Oberregierungsrat und zugleich Schriftleiter des Regierungsblattes, 1923-1933 Mitglied des Aufsichtsrats der Schwaben Verlag AG, 1924-1933 Mitglied des württembergischen Landtags, 1924-1933 Staatsminister der Justiz, 1928-1930 zugleich Staatsminister für Wirtschaft, Bevollmächtigter beim Reichsrat in Berlin, 1934 Hilfsrichter (ab 1935 Leiter eines Senats) beim Oberlandesgericht Stuttgart, 1945 Landesdirektor für Justiz in der von der französischen Militärregierung eingesetzten deutschen Landesverwaltung für Württemberg in Stuttgart, Mitbegründer der Christlich-Sozialen Volkspartei (CSVP) für Nordwürttemberg, 1945-1951 Staatsminister des Justizministeriums von Württemberg Baden, 1949 zugleich stellvertretender Ministerpräsident. Zu ihm: Frank RaberG, „Vielleicht wird ein Höherer unsere Arbeit segnen“. Josef Beyerle und die politische Neuordnung in Württemberg 1945, in: ZWLG 55 (1996) S. 344-361; RABERG, Biographisches Handbuch (wie Anm. 2) S. 67-69. 
tionalsozialisten gelandet sei, die sich nicht scheuten, ihn jetzt sogar in Württemberg als Redner auftreten zu lassen“33.

Die Auseinandersetzung zwischen Hitler und Bolz in Württemberg hatte zur Folge, dass Reichsinnenminister Wilhelm Frick (1877-1946) ${ }^{34}$ die Drohung aussprach, die württembergische Regierung zu entmündigen, das Land gewissermaßen zu annektieren: „Nun haben in den letzten Tagen Staatspräsident und Polizeiverwaltung eines Landes es für richtig angesehen, den Aufruf der Reichsregierung als phrasenreiches inhaltsloses Machwerk zu bezeichnen, und bald darauf wurde die Übertragung der Rundfunkrede des Reichskanzlers gestört und z.T. verhindert. Auch ließ eine Landesregierung es zu, daß in einem marxistischen Plakatanschlag einem aktiven Reichsminister wider besseres Wissen Kriegsdrückebergerei vorgeworfen ist. Diese Landesregierung wird sich nicht wundern dürfen, wenn die Reichsregierung die entsprechenden Folgerungen zöge und dann die Autorität dieser Länderregierung Gefahr liefe. Das will ich im Bewußtsein meiner Verantwortung als Reichsminister nur gesagt haben“. Frick kündigte ein „Eingreifen der Reichsregierung in die Rechte der württembergischen Landesregierung " $\mathrm{an}^{35}$.

Bolz verstand die Drohung, wies sie zurück und hielt dem Reichsinnenminister mit einigem Recht die in Württemberg verhältnismäßig bessere Situation in puncto Wirtschaft, Sicherheit, Ruhe und Ordnung vor: „Was haben wir dem Reich gegenüber gesündigt, daß man uns mit Drohungen kommt? Haben wir eine Verpflichtung dem Reiche gegenüber verletzt? Ist bei uns die Sicherheit und Ordnung bedroht, mehr als in anderen Reichsteilen? Hat die württembergische Regierung, die seit 9 Jahren ohne Marxismus ist, hat diese Regierung irgendwie versagt, oder

${ }^{33}$ Art. „Etwas für Hitler!“ (ohne Erscheinungsort und Datum, vermutlich Deutsches Volksblatt). Ein Exemplar in HStAS Q 1/25 Bü 22.

${ }^{34}$ Gebürtig aus Alsenz (Pfalz), 1896 Studium der Rechtswissenschaften in München, Göttingen, Berlin und Heidelberg, 1901 Promotion in Heidelberg, 1903 Assessorexamen und Aufnahme in den bayerischen Staatsdienst, 1904 Tätigkeit bei der Kreisregierung in Oberbayern und Amtsanwalt bei der Polizeidirektion München, 1907 Bezirksamtsassessor, 1917 Regierungsassessor bei der Polizeidirektion München, 1919 Leiter der Politischen Polizei in München, Unterstützung rechtsradikaler Gruppierungen, enger Kontakt zu Hitler, 1923 Leiter der Münchener Kriminalpolizei, 1924 aufgrund seiner Beteiligung am HitlerPutsch zu 15 Monaten Festungshaft verurteilt, Reichstagsmitglied für die Deutschvölkische Freiheitspartei, aus der Polizei entlassen und Verlust des Beamtenstatus, was allerdings revidiert wurde, 1925 Reichstagsabgeordneter der NSDAP, 1928 Fraktionsvorsitzender, 1930 1931 Innen- und Volksbildungsministers in Thüringen, 1933 Reichsinnenminister, Initiator des „Gesetzes zur Gleichschaltung der Länder mit dem Reich“ und 1934 des „Gesetzes zum Neuaufbau des Reiches“, mit dem die Länder ihre Hoheitsrechte und ihre Volksvertretungen verloren, 1936 beginnender Machtverlust, 1943 Abberufung als Innenminister, 1946 in Nürnberg hingerichtet. Zu ihm: Günter Neliba, Wilhelm Frick. Der Legalist des Unrechtsstaates. Eine politische Biographie, Paderborn u.a. 1992.

35 Art. „Hände weg von Württemberg! Reichsminister Dr. Frick gegen Württemberg. Dr. Bolz und Dr. Brüning antworten“, in: Deutsches Volksblatt, 20. Februar 1933. Ein Exemplar in HStAS Q 1/25 Bü 22. 
ist ihr nicht bestätigt worden, daß sie stets Ordnung gehalten hat und daß diese Ordnung auch heute noch eine gute und vorbildliche ist? Wie kommt man nun dazu, uns zu drohen? Weil ich in Ulm auf dem Parteitag als Privatmann, als Kandidat einer Partei eine etwas scharfe Rede gehalten habe? Ich habe nicht so scharf gesprochen, wie die Redner der Nationalsozialisten in den letzten Jahren gesprochen haben und wie sie auch heute noch reden. [...] Warum passiert es in Preußen, wo doch die Polizei in nationalsozialistischen Händen ist, daß immer wieder Schießereien, Stechereien und Krawalle vorkommen? Warum ist es notwendig, daß immer wieder von diesen Dingen geredet und Drohungen damit verbunden werden? [...] Will man auch noch einen Kampf mit den Ländern heraufbeschwören, wo man alle Energie auf die Beschaffung von Brot und Arbeit verwenden sollte? Man sollte uns doch im Hinblick auf diese Aufgabe in Ruhe lassen, da wir volle Ruhe und Ordnung in unserem Lande haben. Oder droht man uns deshalb, weil man die politische Meinung nicht passend findet, die in gewissen Ländern noch vertreten ist? “36

Zwei Tage später wurde Bolz noch deutlicher: „Im Krieg durften wir die Blutopfer neben den anderen bringen. In der Nachkriegszeit, wo andere zu feig oder zu schwach waren, durften wir eingreifen und jetzt schließt man uns aus und wirft uns den Vorwurf ,Novemberverbrecher' an den Kopf. Es ist so, das Zentrum vertritt 90 Prozent derer, die katholisch denken und leben. Und da empfinden wir es als eine Schmach, wenn man dem katholischen Volk den Krieg ansagt, wenn man es gegen seinen Willen von der Mitarbeit ausschließt, ihm seine nationale Gesinnung abspricht und ihm sagt, was geleistet worden ist, sei ein Trümmerfeld. Nach dem Krieg, als beinahe die Hälfte des Volkes dem Sozialismus nachgelaufen war, da kam das Bürgertum zu uns und hat uns gebeten, wir sollen doch an der Seite der Sozialdemokraten mitarbeiten, damit wenigstens ein gewisser Hemmschuh da wäre gegen die Durchführung des Sozialismus in Staat und Wirtschaft. [...] Was uns noch stärker bewegt, das ist die gegenwärtige Entwicklung unserer innenpolitischen Lage. Wir haben die Furcht, daß aus dem Bürgerkrieg im Kleinen durch eine falsche Innenpolitik ein Bürgerkrieg im Großen entsteht. [...] Der Nationalsozialismus hat vorläufig gar keine Zeit, sich zu sehr mit wirtschaftlichen Fragen zu befassen. Er will vor allem den nationalsozialistischen Staat einrichten, und was wir in Preußen in der Beamtenpolitik sehen, ist gar nichts anderes als die Untermauerung des nationalsozialistischen Staates. Wollten gar konservative Kräfte die Achtung vor der Verfassung und vor dem Recht außer Acht lassen, so würde sich das schwer rächen“. Bolz warnte vor den Gefahren des im Wesen des Nationalsozialismus liegenden Allmachtanspruchs nach dem Muster des italienischen Faschismus. „Als das Zentrum mit den Nationalsozialisten verhandelte, hat es Wert

36 Art. „Warum droht man uns? Staatspräsident Dr. Bolz fragt den Reichsminister Er warnt vor gefährlichen Reden“, in: Deutsches Volksblatt, 25. Februar 1933. Ein Exemplar in HStAS Q 1/25 Bü 22. 
darauf gelegt, daß die Deutschnationalen auch dabei sind. Das haben wir für wichtig gehalten, [...] weil uns die Sache allein allzu gewagt vorkam. Aber die Deutschnationalen blieben stur und wir sehen das Unglück nun darin, daß diese falsche Politik der Deutschnationalen nun zu einem gewaltigen Aufschwung der radikalen Rechten geführt hat, an dem die Deutschnationalen wahrscheinlich wenig Freude haben werden “37. Noch im März bäumte sich Bolz gegen den Nationalsozialismus auf und nannte dessen „Spitzelsystem“ und die Einschüchterung von Beamten ärmlich und erbärmlich ${ }^{38}$.

\section{III.}

Das Ergebnis der Wahlen vom März 1933 setzten die Regierung Bolz aufgrund der riesigen Zugewinne der NSDAP unter Druck, zumal die württembergische Zentrumspartei ihre Stimmen zwar absolut sogar steigern konnte, prozentual aber erhebliche Verluste hinnehmen musste ${ }^{39}$. Die NSDAP machte ihren Anspruch auf das Amt des Staatspräsidenten und die Regierungsbildung geltend und drängte Bolz auf brutale und beschämende Weise aus dem Amt. Ihm folgte im Amt Gauleiter Wilhelm Murr (1888-1945) ${ }^{40}$, ein Fanatiker, der gleich in seiner Antrittsrede Drohungen gegen Bolz und die Mitglieder der früheren Regierung ausstieß ${ }^{41}$. Ende

37 Art. „Wacht auf, erkennt die Zeichen der Zeit! Staatspräsident Bolz in Abtsgmünd“, in: Deutsches Volksblatt, 27. Februar 1933. Ein Exemplar in HStAS Q 1/25 Bü 22. - Wie sehr noch in diesem letzten Wahlkampf der Klerus an der Seite des Zentrums stand, zeigten in diesem Falle etwa die „freudig gestimmten Grußworte“, die der Ortspfarrer an die anwesenden 600 Anhänger der Zentrumspartei richtete.

38 Vgl. Hagen, Eugen Bolz (wie Anm. 3) S.232 mit Bezug auf einen Artikel im Schwäbischen Merkur vom 3. März 1933.

39 Thomas Schnabel, das Wahlverhalten der Katholiken in Württemberg 1928-1933, in: Rottenburger Jahrbuch für Kirchengeschichte 2 (1983) S. 103-114, hier S. 113 (Tabelle).

40 Gebürtig aus Esslingen, evangelisch (1942 Kirchenaustritt), nach der Volksschule kaufmännische Lehre und Angestellter in einer Großhandlung in Esslingen, 1908-1910 Militärdienst, 1914-1918 Kriegsdienst, 1919-1930 Büroangestellter und 1926-1930 Mitglied des Betriebsrats der Maschinenfabrik in Esslingen, um 1930 Arbeitsrichter in Esslingen, seit 1918/1919 Mitglied des Deutsch-Völkischen Schutz- und Trutzbundes, 1922 Mitglied der NSDAP, 1923 Ortsgruppenleiter in Esslingen, 1925 abermals Mitglied der NSDAP, 1928 Gaupropagandaleiter und NS-Gauleiter in Württemberg, 1932-1933 Mitglied des württembergischen Landtags, 15. März 1933 württembergische Staatspräsident und Staatsminister des Innern und der Wirtschaft, 11. Mai 1933 Reichsstatthalter in Württemberg, 1933-1945 Mitglied des Reichstags, 1939 Reichsverteidigungskommissar im Wehrkreis V (Stuttgart). $\mathrm{Zu}$ ihm: Joachim Scholtyseck, „Der Mann aus dem Volk“. Wilhelm Murr, Gauleiter und Reichsstatthalter in Württemberg-Hohenzollern, in: Michael Kissener/Joachim ScholtySECK (Hg.), Die Führer der Provinz. NS-Biographien aus Baden und Württemberg, Konstanz 1999, S. 477-502; Paul SAuER, Wilhelm Murr. Hitlers Statthalter in Württemberg, Tübingen 1998/2000; RABERG, Biographisches Handbuch (wie Anm. 2) S. $595 \mathrm{f}$.

${ }^{41}$ Miller, Eugen Bolz (wie Anm.3) S. 440. 
März 1933 wurde der württembergische Landtag durch das Gesetz der Gleichschaltung der Länder mit dem Reich aufgelöst, Staatspräsident Murr am 5. Mai zum Reichstatthalter für Württemberg ernannt ${ }^{42}$.

Noch war Bolz Abgeordneter des Reichstags; sein Landtagsmandat legte er Anfang Juni nieder ${ }^{43}$. Doch in Württemberg wollte man ihn nun ganz loswerden. Anlass zur Hetze gab ein Anfang Mai erfolgter Besuch beim Parteitag der Christlich-Sozialen Partei Österreichs in Salzburg, auf dem Bolz ein Grußwort sprach ${ }^{44}$. Aufgrund von Drohungen und Warnungen verließ Bolz Mitte Juni Stuttgart und fuhr nach Berlin, kehrte aber am 18. Juni zurück, weil eine Vorladung des Polizeipräsidiums vorlag. Am Morgen des 19. Juni ging er morgens noch zur Kirche, dann, nach dem Frühstück, ins Polizeipräsidium, ahnend, dass er von dort nicht mehr zurückkehren werde ${ }^{45}$. Schon vor dem Polizeipräsidium kam es gegen den ehemaligen Staatspräsidenten zu wüsten Ausschreitungen. Gegen Mittag füllte sich der Platz mit offenbar herbeigeorderten jungen Leuten. Eingeübte Sprechchöre riefen unter anderem: „Heraus mit Bolz! Nieder mit dem Landesverräter!“ Beim Verlassen des Gebäudes wurde Bolz mit stürmischen Pfuirufen und wieder mit dem Ruf „Landesverräter“ empfangen. Die Menge durchbrach die Absperrung und konnte nur mit Mühe von Tätlichkeiten abgehalten werden. Bolz wurde „ergriffen, auf einen Wagen gesetzt und mehrere Stunden durch Stuttgart gefahren. Die ,erregte Volksmenge‘ war überall aufgebaut und nahm eine so drohende Haltung an, daß ihn die Polizei in ,Schutzhaft" nahm und in das Gefängnis auf dem Hohenasperg brachte“46. Das „Deutsche Volksblatt“ - die Tageszeitung der Katholiken Württembergs - druckte die ausgedehnten Berichte der braunen Blätter über den angeblichen „Volkswillen“ lediglich ab, um am Ende nur einen eigenen Satz zu schreiben: „Die tief erschütternden gestrigen Vorgänge zu beurteilen, müssen wir unsern Lesern überlassen “47.

Vier Wochen verbrachte Bolz auf dem Hohenasperg in Einzelhaft. Er litt unter der Irreführung und Verblendung des Volkes, auch unter dem Verlust seiner Ehre, an der Sorge um seine Familie. Dazu kam die erzwungene Untätigkeit. Bolz war über Nacht zum Privatmann geworden - ohne Mandat und auch ohne feste

\footnotetext{
${ }^{42}$ Vgl. ebd., S. 451.

43 Ebd.

${ }^{44}$ Vgl. ebd., S. 454 f., 457.

45 Seiner Frau sagte er beim Abschied: „Du wirst sehen, ich komme nicht zurück. Ich werde es zu ertragen wissen. Sei auch Du ruhig!“ Miller, Eugen Bolz (wie Anm.3) S. 458.

46 „Das geschah dem Mann, der jahrelang als Minister und Staatspräsident eine zwar unpopuläre, aber vorbildliche Verwaltung durchgesetzt und erreicht hatte, daß Württemberg von allen Ländern das einzige war, das nach 1920 keine neuen Schulden gemacht hatte, einem Mann, der zwölf Jahre lang ununterbrochen mit der Rechten im Kabinett zusammengesessen und sich geweigert hatte, die Sozialdemokraten ins Kabinett aufzunehmen“. Heinrich BRÜNING, Memoiren 1918-1934, Stuttgart 1970, S.671.

47 Art. „Dr. Bolz in Schutzhaft“, in: Deutsches Volksblatt vom 20. Juni 1933. - Zum Ganzen Miller, Eugen Bolz (wie Anm. 3) S. 458-460.
} 
Anstellung. Nach der Auflösung der Zentrumspartei hatte er es abgelehnt, weiterhin dem Reichstag als Hospitant der NSDAP anzugehören ${ }^{48}$.

Aus der Haft entlassen, fand Bolz zunächst für sechs Wochen Zuflucht in der Benediktinerabtei Beuron, wo er körperlich wie seelisch wieder zu Kräften kam ${ }^{49}$. Hatte er anfangs noch geglaubt, die Nationalsozialisten könnten schon allein in wirtschaftlicher Hinsicht kein Jahr durchhalten ${ }^{50}$, so war er schon 1934 vollkommen desillusioniert, obwohl er die durch Aufrüstung erzielten wirtschaftlichen Scheinerfolge von 1935-1938 durchschaute ${ }^{51}$. Ständig von der Gestapo beobachtet, in seinem Briefverkehr und in seinen Kontakten überwacht ${ }^{52}$, erfuhr er eine Art „Brachzeit ${ }^{* 53}$, auch wenn er sich schließlich zur Tätigkeit in einem Vaihinger Wirtschaftsunternehmen entschloss, das Filialen in München und am Rhein besaß. Möglicherweise um der steten Beobachtung zu entgehen, war Bolz viel auf Reisen $^{54}$.

Die Familie hatte mit den üblichen Schwierigkeiten zu kämpfen. Als Tochter Mechthild (1922-2011) ${ }^{55}$ im Juni 1935 aus der Schule eine von den Eltern zu unterzeichnende Beitrittswerbung für den BDM mitbrachte, schrieb Bolz in einem

${ }^{48}$ Miller, Eugen Bolz (wie Anm.3) S. 456.

49 Ebd., S.462. - Über die Kontakte nach Beuron, wo das Ehepaar Bolz 1920 geheiratet hatte: Thomas Jansen, Wider den „Irrwahn“ der Massen: Erzabt Raphael Walzer und Dr. Eugen Bolz als Gegner des Nationalsozialismus, in: Jakobus Kaffanke/Joachim KöHLER (Hg.), Mehr nützen als herrschen! Raphael Walzer OSB, Erzabt von Beuron, 1918-1937 (Beiträge zu Theologie, Kirche und Gesellschaft im 20. Jahrhundert, Bd. 17), Berlin 22010, S. $295-332$.

50 Miller, Eugen Bolz (wie Anm.3) S. 444.

51 Ebd., S. 465.

52 Ebd., S. 462. Miller weist auf entsprechende Hinweise in den Briefen hin: „Nun bin ich eigentlich mit meinem Brief wieder fertig. Nicht, weil ich Dir nichts zu sagen hätte, sondern weil ich nichts zu sagen traue“. Ebd., S. 469.

${ }^{53}$ Zunächst plante Bolz, sich den Frauenkongregationen der Diözese als Rechtsberater zur Verfügung zu stellen. Seinen Plan besprach er u. a. mit Domkapitular Kaim, wohl mit negativem Ausgang. „Aber am Ende muß es was werden, daß ich nicht phlegmatischer bin. Es ging auch mit Nichtstun. Viele würden sich dabei wohl fühlen. Und mir ist es wie eine Krankheit, die in Geist u[nd] Körper herumschleicht“. 11. März 1934 Bolz, Stuttgart, an Maria Bolz. HStAS Q 1/25 Bü 33.

${ }^{54}$ Miller, Eugen Bolz (wie Anm.3) S. 465. - Zunächst hatte er daran gedacht, einen Beratungs- bzw. Verwaltungsdienst für Schwesternkongregationen aufzubauen, die durch die Steuerpraktiken des Dritten Reichs zunehmend in Schwierigkeiten gerieten.

55 Mechthild Bolz (1922-2011), 1932-1940 Besuch des Mädchengymnasiums in Stuttgart, danach sechs Monate Arbeitsdienst und drei Monate Krankenpflegedienst, auf Anraten ihres Vaters Studium der Medizin in Tübingen, wo ihr der Leiter des NS-Dozentenbundes, Wetzel, große Schwierigkeiten machte, im Frühjahr 1943 Physikum, danach zwei Semester Studium in Wien, im Sommer 1944 in Freiburg, anschließend Rückkehr nach Tübingen und Staatsexamen sowie Promotion 1946 in Tübingen, im selben Jahr auch Heirat mit dem 15 Jahre älteren, aus Biberach stammenden Ingenieur Otto Rupf, der 1947 den Familiennamen Rupf-Bolz annahm. Freundliche Auskunft von Herrn Eugen Rupf-Bolz (Ulm). 
seiner Briefe: „Mechthild war etwas aufgeregt. Ich beruhigte sie und erklärte ihr, was Charakter heißt! ${ }^{* 56}$ Als ihr und einer Mitschülerin später die Zulassung zur Reifeprüfung versagt wurde, weil sie nicht dem BDM angehörten, setzte sich Bolz mit Erfolg im Kultministerium zur Wehr ${ }^{57}$.

In dieser Zeit der politischen Passivität fand Bolz - dies zeigen die erhaltenen Briefe an seine Frau Maria $(1882-1948)^{58}$ - zu einer noch größeren Innerlichkeit, $\mathrm{zu}$ charakterlicher und religiöser Reife. Beispielhaft sei aus einigen wenigen Briefen zitiert. Im Oktober 1934 schrieb er: „Wenn wir jetzt herbe Tage mitmachen müssen, so wollen wir sie zur Prüfung und Läuterung benützen und das Vertrauen auf Gott bestärken. Ihm verdanken wir die guten Tage. Er schickt uns auch die weniger guten. Wir wollen auch an diesen Tagen Gott loben und ihm danken. Freilich läßt unser Fühlen manchmal uns zaghaft und kleinmütig werden. Dabei wollen wir aber die Grundhaltung des Gottvertrauens nicht verlieren “59. Im August 1935: „Innerlich bin ich aufgeräumt. Mehr als je lebt in mir der Glaube und die Hoffnung, daß ich noch andere Zeiten erlebe und daß meine Passivität nicht mein ferneres Schicksal ist. Ich will ausreifen und ich spüre etwas dessen in mir “60. Am 30. Dezember 1937 ließ er seine Frau aus Oberstdorf wissen: „Der Abschied eines Jahres wird mir immer schwer. Noch nie habe ich es fertiggebracht, in ausgelas-

56 17. Juni 1935 Bolz, Stuttgart, an Maria Bolz. Zit. nach Miller, Eugen Bolz (wie Anm.3) S. $470 \mathrm{f}$.

57 Ebd., S. 471. - Am 10.Februar 1940 ließ Kultminister Mergenthaler die Ministerialabteilung für die höheren Schulen wissen, er „betrachte die Bitte der Tochter des früheren Staatspräsidenten Bolz um Zulassung zur Reifeprüfung, trotzdem sie nicht dem BdM. angehört, im Hinblick auf die frühere politische Stellung und Tätigkeit ihres Vaters als Sonderfall“. In Absprache mit Murr genehmige er die Zulassung zur Reifeprüfung. Abgedr. bei Mascha RiePL-Schмidt, Die ersten 40 Jahre des Hölderlin-Gymnasiums - einst Württembergs erstes „Mädchengymnasium“, in: 100 Jahre Hölderlin-Gymnasium Stuttgart. Festschrift, Stuttgart 1999, S.21-47, hier 44. Fraglich erscheint allerdings die von RieplSchmidt S. 47 geäußerte Vermutung, Rektor Otto Ostertal habe sich gegen den Ausschluss von Mechthild Bolz von der Reifeprüfung eingesetzt. Nach späteren Schilderungen von Mechthild Bolz war Ostertag ein überzeugter Nationalsozialist, der auch Gedichte auf den „Führer“ schrieb. Freundliche Mitteilung von Herrn Eugen Rupf-Bolz (Ulm).

58 Gebürtige Höneß aus Ulm, Tochter eines Hoteliers und Wirts in Ulm, Studium der Neuphilologie u.a. an der Sorbonne in Paris, Oberlehrerin bzw. Studienrätin in Düren (Westfalen). Bolz lernte sie während seiner Militärdienstzeit in Ulm 1905/1906 kennen, 1920 Heirat und Umzug nach Stuttgart zunächst in eine Dienstwohnung im Justizministerium, 1927 in ein Mietshaus, 1932 in ein eigenes Haus am Kriegbergturm, ab 1928 Mitwirkung in zahlreichen Vereinen und Verbänden, Wahrnehmung von Repräsentationspflichten, nach 1945 Eintritt in die CDU, 1947 Wahl in den Stuttgarter Gemeinderat. Zu ihr: Frank Raberg, Biografisches Lexikon für Ulm und Neu-Ulm [1802-2009], hg. von den Stadtarchiven Ulm und Neu-Ulm, Ostfildern 2010, S. $47 \mathrm{f}$.

59 10. Oktober 1934 Bolz, Beuron, an Maria Bolz. Zit. nach Miller, Eugen Bolz (wie Anm.3) S. 472.

${ }^{60}$ August 1935 Bolz, Stuttgart, an Maria Bolz. Zit. nach Miller, Eugen Bolz (wie Anm.3) S. 471. 
sener Freude ein neues Jahr zu begrüßen, als ob das alte nicht gewesen wäre. [...] Die rechte Art einer Neujahrsfeier ist die Besinnlichkeit. Aber wenn man unsern Herrgott abschaffen will und wenn man überall die Nöte mit Freudenfesten zudecken will, dann ist solche Predigt fehl am Platze. Wir wollen anders sein. Trotz der mancherlei Sorgen des alten Jahres wollen wir die Überfülle von Schönem und Gutem anerkennen, unserem Herrgott danken und ihn bitten um die Kraft, alles würdig hinzunehmen, was das neue Jahr auch bringen mag“61. Im August 1938: „Welche Zeit der Entwicklung und der persönlichen Erlebnisse! Welche Sorgen! [...] In der schweren Gegenwart wollen wir unsere Hoffnung auf Gott setzen und die Zeit zur geistigen Ausreife benützen, damit wir das Kommende - sei es gut, sei es bös - zu ertragen wissen. Obwohl unser Streben nach Kraft- und Zeitaufwand gezwungenermaßen vorwiegend aufs Zeitliche gerichtet war und ist, so ist doch der Untergrund aufs Ewige abgestellt. Je älter man wird, desto mehr. Am 15. August [Mariä Himmelfahrt, der Verlobungstag] wollen wir gemeinsam beten, damit unser Herrgott uns auch das Kommende gemeinsam erleben und ertragen lasse. Wir schulden Dank!“62. An Silvester 1938: „Und das Neue? Dunkel liegt es vor uns. Wir wollen nicht viel darüber brüten und unserem Herrgott vertrauen. Je mehr ich meine Freiheit beschränkt sehe, desto größer ist der Antrieb, mich auf mein Inneres zurückzuziehen. [...] Es wäre zum Verzweifeln, wenn man nicht Aussicht auf ein anderes Leben hätte und das diesseitige nur als Übergang betrachten könnte“63. Im August 1939: „Immerhin erfüllt mich die Zuspitzung der Lage [am 1. September erfolgte der Überfall auf Polen] mit Sorge. Aber das Gottvertrauen verläßt mich nicht. Dem Leben gegenüber wird man immer gleichgültiger" ${ }^{64}$.

Die Innerlichkeit von Bolz, sein reifender Glaube, ermöglichte ihm erst das, was man „Resistenz“ oder „Widerstand“ nennen könnte. Je länger das „Dritte Reich“ dauerte, desto düsterer beurteilte er die Lage, desto mehr Potential setzte er jedoch auch frei, an Veränderung zu denken. In Stuttgart, aber auch auf seinen vielen Reisen, suchte er wieder Verbindung mit früheren Mitstreitern. Bei den Treffen Carl Friedrich Goerdelers $(1884-1945)^{65}$, des Führers des bedeutendsten Widerstands-

61 Ebd., S. $474 f$.

62 Ebd., S. 472 f.

${ }^{63}$ Ebd., S. 475.

${ }^{64}$ Ebd., S. 475.

65 Karl Friedrich Goerdeler (1884-1945), gebürtig aus Schneidemühlen (Posen), Jurastudium in Tübingen, Königsberg und Göttingen, 1911 Heirat, 1920 zweiter Bürgermeister von Königsberg, Eintritt in die die DNVP, 1930 Oberbürgermeister von Leipzig, 1931/1932 unter Brüning Reichskommissar zur Überwachung der Preise, 1934 erneute Berufung zum Reichspreiskommissar, 1935 von Hitler entlassen, 1937 aus Protest Rücktritt als Oberbürgermeister von Leipzig, wirtschaftspolitischer Berater der Robert Bosch GmbH, 1937-1939 zahlreiche Auslandsreisen, 1939 Rückkehr nach Deutschland und führender Vertreter des konservativen Widerstands gegen Hitler, 1940 Beteiligung an Planungen der Gruppe um Ulrich von Hassel für einen Staatsstreich zur Ausschaltung Hitlers, 1934 Versuch, eine Ver- 
kreises, mit dem früheren Reichskanzler Heinrich Brüning im Ausland wurde immer auch von Bolz gesprochen. Ab 1942 standen Goerdeler und Bolz in Verbindung, Bolz erfuhr von den militärischen Widerstandskräften ${ }^{66}$. Gewissensnot empfand Bolz angesichts dieser Widerstandspläne wohl nicht. Über die Gründe kann uns eine Rede Aufschluss geben, die Bolz 1928 bei der Feier der Stuttgarter Katholiken zum Diözesanjubiläum gehalten hatte. Hier hatte er zwar ausgeführt, ein guter Katholik müsse auch ein guter Staatsbürger sein, der den Gesetzen Gehorsam leiste und keine revolutionäre Gesinnung übe. Doch hatte er damals hinzugefügt: „Er [der Katholik] arbeitet mit am Aufbau des Staates und seinen wirtschaftlichen und sozialen Verhältnissen. Nur e in e Schranke gibt es, den Verstoß des Staatsgesetzes gegen Gottes Gesetz“67. Damit waren Recht und Pflicht zum passiven Widerstand formuliert. 1934 war Bolz noch einen entscheidenden Schritt weitergegangen, als er auch ein aktives Widerstandsrecht formulierte, unter Voraussetzungen, die er klar definierte, nämlich „bei offensichtlichem und dauerndem Mißbrauch der Staatsgewalt“. „Da das Gemeinwohl, ,nächst Gott das erste und letzte Gesetz in der staatlichen Gemeinschaft ${ }^{`}$ (Papst Leo XIII.), Ursache und Ziel des Staates ist, so kann die Befehls- und Zwangsgewalt des Staates nur so weit reichen, als diese dem Gemeinwohl dient [...]. Bei offensichtlichem und dauerndem Mißbrauch der Staatsgewalt besteht ein Notwehrrecht des Volkes“"68.

Die äußere Entwicklung der kommenden Jahre und die Bereitschaft von Bolz, der Regierung nach einem Sturz Hitlers zur Verfügung zu stehen, sind soweit bekannt $^{69}$. Im September 1941 schrieb er seiner Frau, die sich am Bodensee aufhielt,

ständigung mit den Westmächten vorzubereiten, Planungen für eine Regierung nach dem Sturz des NS-Regimes, am 18. Juli 1944 Flucht vor der Verhaftung durch die Gestapo nach Westpreußen, am 12. August erkannt und festgenommen, am 8. September zum Tode verurteilt und am 2. Februar 1945 hingerichtet. Zu ihm: Gerhard RitTer, Carl Goerdeler und die deutsche Widerstandsbewegung. Mit einem Brief Goerdelers in Faksimile, Stuttgart ${ }^{4}$ 1984; Sabine Gillmann (Hg.), Politische Schriften und Briefe Carl Friedrich Goerdelers, 2 Bde., München 2003; Peter Hoffmann, Carl Goerdeler gegen die Verfolgung der Juden, Köln 2013.

${ }^{66}$ Miller, Eugen Bolz (wie Anm.3) S. 478, 480 f. - Hier auch Näheres. Die Datierung der Kontakte Bolz - Goerdeler auf 1941/1942 sind wohl um ein Jahr zu früh angesetzt.

67 Ebd., S. 482 f.

68 Ebd.

${ }^{69}$ Vgl. ebd., S. 489-492; Joachim Scholtyseck, Der „Stuttgarter Kreis“. Ein Mikrokosmos des Widerstands gegen den Nationalsozialismus, in: Klaus EIsELE/Rolf-Ulrich KunZE (Hg.), Mitverschwörer - Mitgestalter. Der 20. Juli im deutschen Südwesten, Konstanz 2004, S. 59-106, insbes. S.62-65, 76f., 81-85. - Bolz war sich der Gefährlichkeit des Unternehmens freilich bewusst. Vgl. Miller, Eugen Bolz (wie Anm.3) S.486, der folgendes Zwiegespräch zwischen Bolz und der mit der Familie befreundeten Zentrumspolitikerin Helene Weber mitteilt, das sich in Anwesenheit von Maria Bolz im November 1943 in Berlin ergab. Weber: „Wissen Sie, daß Sie jetzt gefährlich leben?“ - „Das weiß ich.“ - „Sie setzen Ihr Leben aufs Spiel.“ - „Das weiß ich, und wenn ich umkomme, mein Leben ist nichts, wenn es um Deutschland geht. Auch meine Sicherheit ist nichts, wenn es um die deutsche Sicherheit geht. Ich kann nicht anders. Ich muß dabei sein.“ 
zum Geburtstag: „Ich kann das Gefühl nicht los werden, daß wir in immer schnellerem Schritt aufs Letzte losmarschieren. Der Gedanke daran ist schwer. Möge Gottes Güte es fügen, daß wir, in den Jahren nicht weit auseinander, das uns zugemessene Maß gemeinsam ableben dürfen. Der Gedanke ans Letzte und die Vorbereitung aufs Letzte, ist unsere vordringlichste Aufgabe. Wir wollen uns darin unterstützen “70. Ob Bolz damals schon in Widerstandspläne bzw. Überlegungen zur Bildung einer Regierung nach dem Ende des Nationalsozialismus eingebunden war, lässt sich nicht sicher sagen; es gibt widersprüchliche Aussagen. So soll nach der einen Version Bolz auf Vermittlung des Zentrumspolitikers und christlichen Gewerkschaftlers Joseph Ersing $(1882-1956)^{71}$ bereits 1941 Goerdeler kennengelernt haben ${ }^{72}$. Nach anderen Informationen nahm Bolz erst im Frühjahr 1942 über Ersing Kontakt zu Goerdeler auf ${ }^{73}$. Wieder eine andere Version bieten die „Kaltenbrunner-Protokolle“. Danach soll Mitte 1942 Goerdeler den früheren Stuttgarter Polizeichef Paul Hahn (1883-1952) ${ }^{74}$ nach vertrauenswürdigen Leuten aus dem

70 Miller, Eugen Bolz (wie Anm. 3) S. $486 \mathrm{f}$.

71 Gebürtig aus Ochsenhausen, katholisch, nach Besuch der Volksschule Schreinerlehre, 1899-1902 auf Wanderschaft, erste Kontakte mit der christlichen Gewerkschaftsbewegung, Besuch von Fortbildungskursen beim Volksverein für das katholische Deutschland in Mönchengladbach, 1906 Bezirksleiter im Christlichen Holzarbeiterverband Mannheim, später in Frankfurt, 1911 in Karlsruhe, Teilnahme am Ersten Weltkrieg, 1919/1920 Mitglied der Weimarer Nationalversammlung, bis 1933 Reichstagsabgeordneter des Zentrums, zugleich auch Gewerkschaftssekretär in Karlsruhe, 1930-1933 auch Mitglied der Senats der Kaiser-Wilhelm-Gesellschaft, seit 1934 in engem Kontakt mit Jakob Kaiser, auch zu sozialdemokratischen Kreisen um Jakob Weimer (zu ihm vgl. unten), Kontakte zu Goerdeler und Bolz, am 5. Oktober 1944 verhaftet und in Berlin inhaftiert, später in Fürstenberg, am 19. Oktober ins KZ Ravensbrück verbracht, wo er Bolz traf und sich mit diesem über die Verhöre absprechen konnte, einer Verurteilung entging er, weil seine Prozessakten durch Bombenangriff vernichtet wurden, 1945 Mitbegründer der CDU in Württemberg-Baden, 1946 Mitglied der Vorläufigen Volksvertretung und der Verfassungsgebenden Landesversammlung, bis 1950 Mitglied des Landtags von Württemberg-Baden. Zu ihm vgl. Klaus Eisele, Die „Aktion Goerdeler“, in: Eisele/Kunze, Mitverschwörer - Mitgestalter (wie Anm. 69) S.129-170, hier S.140f.

72 Ebd., S. 135.

73 Scholtyseck, Der „Stuttgarter Kreis“ (wie Anm. 69) S. 63.

74 Gebürtig aus Obertürkheim, evangelisch, in Esslingen aufgewachsen, 1902 Lehrer, 1907 Kunststudium in Stuttgart, 1911 Kunstmaler und Eröffnung einer Werkstatt für graphische Kunst, als Freiwilliger Teilnahme am Ersten Weltkrieg, in der Revolution 1918/1919 Soldatenrat und Befehlshaber der Sicherheitstruppen, beteiligt an der Niederschlagung des Spartakus-Aufstands, des Kapp-Putschs und des Hölz-Auftstands, bis 1923 Oberpolizeidirektor in Stuttgart, dann Wechsel in die Wirtschaft, Gründung einer Möbelfabrik und 1935 Mitarbeiter der Robert Bosch GmbH, seit 1938 Kontakt zum Kreis um Bosch und Goerdeler, mit der Ausarbeitung von Fluchtplänen beauftragt, nach dem 20. Juli 1944 verhaftet, aber nur zu Haft und Ehrverlust verurteilt, Juni bis September 1945 Chef der „deutschen Staatspolizei für Württemberg“. Zu ihm: Eisele, Die „Aktion Goerdeler“ (wie Anm.71) S.147f.; https://de.wikipedia.org/wiki/Paul_Hahn (abgerufen am 20.10.2015). 
Zentrum befragt und dieser ihm Bolz genannt haben ${ }^{75}$. Ab Sommer 1942 fanden alle zwei bis drei Monate Treffen zwischen Bolz und Goerdeler (sowie Ersing) statt, und zwar teils in dem von Ordensschwestern geführten Europäischen Hof in Stuttgart, teils bei einem Neffen Ersings, teils bei Bolz zuhause. In diesen Gesprächen wurde Bolz offenbar näher eingeweiht ${ }^{76}$. Im Herbst 1942 beriet man über die Frage, „ob man den Dingen ihren Lauf lassen oder ein aktives Eingreifen schon jetzt vorbereiten solle“. Man entschied sich für Letzteres und stellte Überlegungen zu einem Schattenkabinett an; Bolz stellte sich als Innenminister zur Verfügung 77. Bolz benannte als möglichen Vertrauensmann für Baden seinen Freund ${ }^{78}$ Rechtsanwalt Reinhold Frank (1896-1945) ${ }^{79}$. Wohl im Februar (vielleicht aber auch schon im Januar) 1943 bat er Frank, sich mit Goerdeler in Verbindung zu setzen, was dieser auch tat ${ }^{80}$. Im Januar 1943 jedenfalls fand in der Berliner Wohnung des früheren Zentrumspolitikers Jakob Kaiser (1888-1961) ${ }^{81}$ ebenfalls eine Unter-

${ }^{75}$ Hans-Adolf Jacobsen (Hg.), „Spiegelbild einer Verschwörung“. Die Opposition gegen Hitler und der Staatsstreich vom 20. Juli 1944 in der SD-Berichterstattung. Geheime Dokumente aus dem ehemaligen Reichssicherheitshauptamt, 2 Bde., Stuttgart 1984, hier S.782.

${ }^{76}$ Ebd., S.784f.

77 Ebd., S. 687.

78 Vgl. ebd., S. $707 \mathrm{f}$.

79 Gebürtig aus Bachhaupten im Hohenzollerischen, katholisch, Besuch des erzbischöflichen Gymnasialkonvikts in Sigmaringen, Freiwilliger im Ersten Weltkrieg, 1919 Studium der Rechtswissenschaften in Freiburg und Tübingen, Promotion, nach der Referendarzeit 1923 Rechtsanwalt in Karlsruhe, verheiratet, vier Kinder, Mitglied der Zentrumspartei, Abgeordneter der Karlsruher Stadtverordnetenversammlung bis 1933, mehrfach Rechtsverteidiger von Verfolgten aus allen politischen und religiösen Bereichen, Bolz nannte ihn Goerdeler als geeignete Person für den Wiederaufbau in Baden, schon ein Tag nach dem Attentat von 20. Juli 1944 verhaftet, am 12. Januar 1945 zum Tod verurteilt und am 23. Januar hingerichtet. Zu ihm: Wolfgang Altgeld, Reinhold Frank. Ein Weg in den Widerstand, in: Reinhold Frank zum fünfzigsten Todestag, hg. von der Stadt Karlsruhe, Karlsruhe 1995, S. 5-26; Michael Kissener, Für das Recht: die Karlsruher Widerstandsgruppe um Reinhold Frank, in: Eisele/Kunze, Mitverschwörer - Mitgestalter (wie Anm. 69) S.29-58; Horst Rehberger, Reinhold Frank. Rechtsanwalt in Karlsruhe, in: Michael Bosch/Wolfgang Niess (Hg.), Der Widerstand im deutschen Südwesten 1933-1945, Stuttgart 1984, S. 299-309; Uwe Schellinger, Dr. Reinhold Frank (1896-1945), in: Helmut Moll (Hg.), Zeugen für Christus. Das deutsche Martyrologium des 20. Jahrhunderts, Paderborn u.a. ${ }^{6} 2015$, S. $292-296$.

80 Jacobsen, „Spiegelbild einer Verschwörung“ (wie Anm.75) S.712. - Im Herbst 1943 kam es zu einem zweiten Treffen zwischen Frank und Goerdeler, bei dem sich Frank für eine künftige Aufgabe zur Verfügung stellte. Ebd., S.712.

${ }^{81}$ Gebürtig aus Hammelburg, katholisch, Mitglied der Zentrumspartei und der Christlichen Gewerkschaftsbewegung, ab 1924 deren Landesgeschäftsführer für das Rheinland und Westfalen, im März 1933 noch ins Parlament gewählt, dem er bis November 1933 angehörte, 1934 Anschluss an die Widerstandsbewegung, 1938 mehrere Monate in Gestapo-Haft, nach 1941 Kontakt mit Goerdeler und führenden Männern der Militäropposition, der Verhaftung nach dem gescheiterten Attentat konnte er durch Flucht entgehen, seine Frau und 
redung statt, in der über die Zusammensetzung der künftigen Reichsregierung beraten wurde ${ }^{82}$. Im Sommer kam Kaiser nach Stuttgart, wo er feststellte, dass Bolz und Ersing kaum mehr auf einen Sturz Hitlers durch das Militär hofften ${ }^{83}$. So hatte Bolz damals vergeblich versucht, seinen früheren Schulkameraden General Hermann Geyer (1882-1946) ${ }^{84}$ für den Widerstand zu gewinnen ${ }^{85}$.

Gleichwohl blieb Bolz auch im Sommer und Herbst 1943 nicht untätig. Von 8. bis 18. Juni 1943 besuchte er - zusammen mit seiner Frau - Wien, wo Tochter Mechthild studierte. Dies sowie ein dichtes kulturelles Programm ${ }^{86}$ sollten darüber hinwegtäuschen, dass es auch um Netzwerkpolitik und politischen Austausch ging ${ }^{87}$. Im Herbst 1943 verdichteten sich dann die Treffen der Beteiligten, die teils in Stuttgart, teils aber auch in Straßburg stattfanden ${ }^{88}$. Im Herbst 1943 soll sich dann

die ältere Tochter kamen in Sippenhaft. 1945 Mitbegründer der CDU in der sowjetischen Besatzungszone, Vertreter des "linken“ Flügels in der Partei, im Dezember 1947 als Vorsitzender der Ost-CDU von den Sowjets abgesetzt, Übersiedelung nach West-Berlin, Mitbegründer der CDU-Sozialausschüsse, bis 1958 deren Vorsitzender, 1949-1957 Bundestagsmitglied und Minister für gesamtdeutsche Fragen. Zu ihm: Elfriede Nebgen, Jakob Kaiser. Der Widerstandskämpfer, Stuttgart u.a. 1967; Werner Conze, Art. Kaiser, in: NDB 11 (1977) Sp. 41-43.

82 Scholtyseck, Der „Stuttgarter Kreis“ (wie Anm.69) S. 63.

83 Ebd., S. 65.

${ }^{84}$ Gebürtig aus Stuttgart, 1900 Eintritt in das Grenadier-Regiment „Königin Olga“, seit 1913 im Generalstab, verschiedene Beförderungen und Funktionen, im November 1918 Mitglied der Waffenstillstands-Kommission, ab März 1919 Mitglied der deutschen Friedensgesandtschaft, nach dem Krieg in die Reichswehr übernommen, 1928 im Reichswehrministerium, 1931 Kommandeur in Braunschweig, 1932 Generalmajor, 1934 Generalleutnant und Kommandeur der 5. Division der Reichswehr, Befehlshaber des Wehrkreises V, 1939 als politisch unzuverlässig verabschiedet, für den Zweiten Weltkrieg wieder reaktiviert, Kommandierender General des IX. Armeekorps, am Westfeldzug und am Krieg gegen die Sowjetunion beteiligt, 1941 Versetzung in die „Führerreserve“, Ende 1943 in den Ruhestand versetzt, seitdem wohnhaft in Höfen a. Enz, im April 1945 Bürgermeister, 1946 Selbstmord. https://de.wikipedia.org/wiki/Hermann_Geyer_(General) (abgerufen am 25.10.2015).

${ }^{85}$ Ebenso erfolglos war sein Bemühen im Frühjahr 1944, Generalfeldmarschall Erwin Rommel (1891-1944) zu rekrutieren. Scholtyseck, Der „Stuttgarter Kreis“ (wie Anm.69) S.76f.

86 Über die gemeinsamen Wiener Tage existiert ein Fotoalbum. Freundliche Auskunft von Eugen Rupf-Bolz (Ulm).

87 Vgl. Jacobsen, „Spiegelbild einer Verschwörung“ (wie Anm. 75) S. 688.

88 Im Elsaß war der Jurist und Verwaltungsfachmann Johann Keppi (1894-1976) der Ansprechpartner, über den die elsässische Resistance eingebunden werden sollte; Keppi traf im April 1944 auch mit Stauffenberg zusammen. Vgl. EIsele, Die „Aktion Goerdeler“ (wie Anm. 71) S. 144, 151; Scholtyseck, Der „Stuttgarter Kreis“ (wie Anm. 69) S. 96. - Bolz hatte zudem Kontakte zu früheren Zentrumspolitikern, die ebenfalls eingeweiht wurden. So wurde Bolz im Spätsommer 1943 und im Mai/Juni 1944 vom ehemaligen Reichsernährungsminister Andreas Hermes (1878-1964) in Stuttgart besucht, „dessen schwankende Haltung" er festigte. Auch zu Christine Teusch (1888-1968) und Helene Weber, zu Kaiser, dem Rechtsanwalt Josef Wirmer (1901-1944) und dem Sozialdemokraten Wilhelm Leuschner (1890-1944) bestanden Kontakte. 
herauskristallisiert haben, dass Bolz nicht das Innen-, sondern das Kultusministerium übernehmen solle ${ }^{89}$. Bolz war über den Attentatsversuch vom November 1943 informiert, im Dezember hielt er sich drei Wochen in der Karlsruher Wohnung Franks auf, wo er das unmittelbar bevorstehende Attentat auf Hitler erwartete. Als es ausblieb, kehrte er kurz vor Weihnachten tief enttäuscht nach Stuttgart zurück ${ }^{90}$. Ein letztes Treffen mit Goerdeler, Ersing und Mitglieder des Bosch-Kreises fand Anfang Juli 1944 in Stuttgart statt ${ }^{91}$.

Infolge des Attentats vom 20. Juli 1944 wurde Bolz, der sich weigerte, sich rechtzeitig durch Flucht zu entziehen ${ }^{92}$, verhaftet und zunächst nach Berlin, dann ins berüchtigte Frauenkonzentrationslager Ravens-

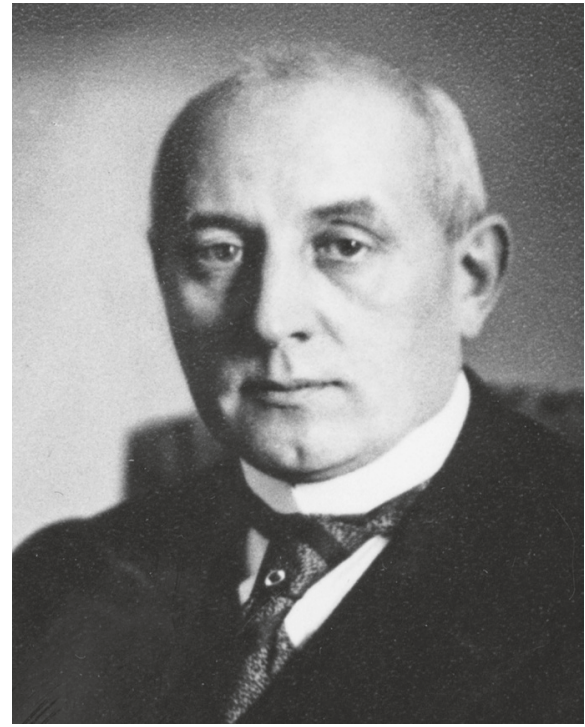

Eugen Bolz (1881-1945) (Vorlage: HStAS Q 1/25 Bü 12). brück gebracht. Er wurde den üblichen Verhören und Folterungen unterworfen. Einer seiner Mitgefangenen sah eines Morgens Bolz in der offenstehenden Zelle, an der er vorübergeführt wurde, und erschrak über sein Aussehen, das die Spuren von Misshandlungen verriet ${ }^{93}$. Am 19. Oktober durften ihn Frau und Tochter besuchen. Bolz war auf ihr Kommen nicht vorbereitet. „Als er uns sah“, berichtete seine Frau, „durchlief ein Zittern seine abgemagerte Gestalt, und er blickte uns mit weit offenen Augen an. Lange versagte die Stimme, die auch nachher noch leise und heiser war. Von sich selbst erzählte er kein Wort ${ }^{\text {“94. }}$.

Die Briefe, die Bolz schreiben durfte, die aber nur unzuverlässig ankamen, wurden einer strengen Zensur unterworfen. Vieles wurde nicht gesagt, durfte nicht gesagt werden. In einem der Briefe an seine Tochter heißt es: „Liebe Mechthild! Du bekommst meinen Brief von der Mutter in die Hand. Darum ein Wort an Dich.

${ }^{89}$ Für das Innenministerium vorgesehen war nun der SPD-Politiker Julius Leber (1891-1945). Vgl. Jacobsen, „Spiegelbild der Verschwörung“ (wie Anm.75) S.210, 688. Nach Eisele, Die „Aktion Goerdeler“ (wie Anm.71) S. 135 f. erklärte sich Bolz im Mai 1944 zur Übernahme des Kultusministeriums für den Fall eines geglückten Attentats bereit.

90 Scholtyseck, Der „Stuttgarter Kreis“ (wie Anm.69) S.77.

91 Ebd., S. 77.

92 Miller, Eugen Bolz (wie Anm. 3) S. $494 \mathrm{f}$.

93 Ebd., S. 497.

94 Ebd., S. 498. 
Vor allem meinen herzlichen Dank, daß Du so treu und fest zur lieben Mutter und mir hältst. Du durchlebst eine schwere Zeit, vielleicht wird sie noch schwerer. Sie wird Dich ausreifen. Leben und Eigentum gelten nichts mehr. Nur die Seele ist unerreichbar für alle äußeren Mächte. Ihr muß unsere ganze Sorge gelten, damit sie gestärkt und veredelt die ernste Zeit überwindet. Wenn in den kommenden Wochen die Flut der Zerstörung noch ansteigt, so wissen wir doch auch, daß auf Flut Ebbe folgt und auf Zerstörung Aufbau“ "95. Am 21. Dezember dann einer der letzten Briefe: „Meine liebste Frau und Tochter! Eine tieftraurige Botschaft habe ich Euch für Weihnachten und Neujahr. Unerwartet war heute Verhandlung in meiner Sache. Ich wurde zum Tode verurteilt! [...] Was ich gefühlt habe, kam. Erbarmungslos. Ich habe mich innerlich, religiös in den Monaten darauf eingestellt. Ich muß von Euch und vom Leben Abschied nehmen. Euch zu verlassen ist mir schwer. Ich bitte Euch, nehmt es hin als das mir von Gott bestimmte Kreuz. Ich habe wenigstens die Gnade, vorbereitet zu sterben und vielleicht einer bösen Zeit zu entgehen. Als ich von der Verhandlung kam, fand ich Eure lieben Weihnachtspakete [...]. Welche Güte und Fülle. Welcher Gegensatz! Allen Dank! - Frau und Tochter! Verzeiht mir meine Schwachheiten und Fehler. Behaltet mich in gutem Andenken. Ich hoffe Euch an einem besseren Ort wiederzusehen. Einstweilen

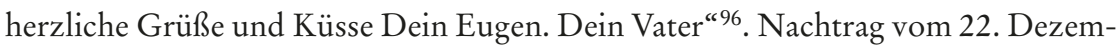
ber: „Ich trage mein Schicksal mit Gleichmut. Tut das gleiche. Unser Herrgott wird Euch helfen. Macht Euch nicht zu viele Sorgen. Eure lieben Geburtstagsbriefe habe ich am Montag erhalten. Wenn ich Eure Liebe vergelten könnte ${ }^{\text {«97. }}$.

\footnotetext{
95 Ebd., S. 502.

96 Ebd., S. $511 \mathrm{f}$.

97 Ebd., S. 512.
} 


\section{Anhang ${ }^{98}$}

\section{Die letzten Tage von Bolz als württembergischer Staatspräsident (März 1933)}

Die künstlich aufgeputschte Stimmung, gegen die sich Bolz immer wieder wandte, fübrte im Vorfeld der Reichstagswahl vom 5. März 1933 zu enormen Verzerrungen. Der den Kommunisten zugeschriebene Reichstagsbrand vom 27. Februar gab Hitler den Anlass, die bisherigen Freibeiten nicht nur aufzubeben, sondern mit dem Schreckgespenst des Kommunismus die Wablpropaganda und den damit verbundenen Terror ins Extrem zu steigern. In diesem Zusammenhang ist auch der von Hitler erhobene Vorwurf gegen Bolz zu seben, in der Vergangenheit mit den Kommunisten kollaboriert zu haben. Möglicherweise ging es neben der Desavonierung des Staatspräsidenten - ganz realpolitisch - darum, einem rein rechnerisch denkbaren Zusammengeben der Regierungskoalition mit den Kommunisten zur Verhinderung der Nationalsozialisten in den Ländern vorzubeugen. Der Wablkampf selbst wurde mit undemokratischen Mitteln ausgefochten. Nach dem überwältigenden Sieg der Nationalsozialisten im Reich wurde noch in der Nacht vom 5. auf den 6. März die Parole zur Übernabme der Macht auch in den Ländern ausgegeben: Die süddeutschen Regierungen hätten kein Recht mehr, die Volksvertretung für sich zu beanspruchen. Am Abend des 6. März forderten auf dem Stuttgarter Marktplatz die „Gewinner" in Württemberg, Wilhelm Murr und Christian Mergenthaler (1884-1980) ${ }^{99}$, die Entfernung von Staatspräsident Bolz. Am 7. März erzwangen die Nationalsozialisten das symbolträchtige Hissen der Hakenkreuzfabne auf dem Landtag, den Ministerien und den öffentlichen Gebäuden. Am 8. März ernannte Reichsinnenminister Frick, wie schon im Wablkampf angedeutet ${ }^{100}$, für Württemberg einen "Reichspolizeikommissar", was einer faktischen Entmachtung der

${ }^{98}$ Die Edition erfolgt buchstabengetreu. Offensichtliche Verschreibungen (Groß-/ Kleinschreibung etc.) wurden stillschweigend korrigiert.

99 Gebürtig aus Waiblingen, evangelisch, nach der Realschule und Oberrealschule 1902-1907 Studium der Physik und Mathematik an der TH Stuttgart, in Göttingen und Tübingen, 1908-1909freiwilliges Militärdienstjahr, 1909-1911 unanständige Verwendung im württembergischen höheren Schuldienst, 1911 Oberreallehrer in Leonberg, 1917 in Stuttgart, 1914-1918 Kriegsdienst, 1920 Professor für Mathematik und Physik am Realgymnasium und an der Oberrealschule Schwäbisch Hall, seit 1929 am Gymnasium und Realgymnasium Bad Cannstatt, 1922 Mitbegründer und Vorsitzender der NSDAP-Ortsgruppe Schwäbisch Hall, Mitglied der SA, 1924 „Gauführer der Nationalsozialistischen Freiheitsbewegung“, 1924-1933 Mitglied des württembergischen Landtags, 1924 auch Mitglied des Reichstags, Juni 1927 erneut Mitglied der NSDAP, 15. März bis 12. Mai 1933 Staatsminister für Kirche und Schule und stellvertretender Staatspräsident, 12. Mai 1933 württembergischer Ministerpräsident und Staatsminister für Kirche und Schule, 1945 in Internierungshaft, 1948 als Hauptschuldiger eingestuft, 1949 aus der Haft entlassen. Zu ihm: Michael Stolle, Der schwäbische Schulmeister. Christian Mergenthaler, Württembergischer Ministerpräsident, Justiz- und Kultusminister, in: Kissener/Scholtyseck, Die Führer (wie Anm. 40) S. 445-475; RABERG, Biographisches Handbuch (wie Anm. 2) S. 562 f. 100 Vgl. oben. 
noch amtierenden legalen Regierung gleichkam. Als Grund wurde vorgeschoben, die Aufrechterhaltung der öffentlichen Sicherheit und Ordnung in Württemberg sei unter der gegenwärtigen Leitung der Polizei nicht mehr gewährleistet. Die Regierung beschloss zwar am 9. März, Rechtsverwahrung beim Reichspräsidenten einzulegen und beim Staatsgerichtshof Klage zu erheben, doch die Ereignisse überschlugen sich. Der bereits anf 11. März festgesetzte Zusammentritt des Landtags wurde von dem Polizeikommissar wegen des Gerangels innerhalb der Nationalsozialisten um die Regierungsposten aufgeschoben; die Minister, die sich bereits von ibren Ministerien verabschiedet hatten, mussten noch einmal die Arbeit aufnehmen. Erst am 15. März wäblte der Landtag, der nur ein einziges Mal zusammentrat, Murr zum newen Staatspräsidenten. Die Abgeordneten der Zentrumspartei und der Demokratischen Partei hatten weiße Stimmzettel abgegeben. Am 8. Juni 1933 wurde ein „Ermächtigungsgesetz" für Württemberg verabschiedet. Das "Gesetz über den Nenaufbau des Reichs"vom 30. Januar 1934 eliminierte schließlich den Landtag.

Der folgende Bericht von Maria Bolz - gerichtet an die Verwandtschaft - gibt aus eigenem Erleben einen detaillierten Einblick in die dramatischen Vorgänge zwischen der Reichstagswabl und dem Ausscheiden von Eugen Bolz aus dem Amt des Staatspräsidenten.

Maria Bolz an Verwandte, 13. März 1933

Maschinenschriftlicher Brief, 4 Seiten. Ohne Unterschrift.

HStAS Q 1/25 Bü 36.

Stuttgart, 13.3.1933

Meine Lieben!

heute will ich einmal versuchen, Euch einen kleinen Überblick über die letzten Ereignisse zu geben.

Was vor den Wahlen lag, wisst Ihr ja. Meiner Ansicht nach, war es ein Fehler, dass Eugens Rede vom Parteitag in Ulm ${ }^{101}$ in die Presse kam. Gewiss hat er für sein freimütiges Eintreten in vielen Kreisen Anerkennung gefunden, aber rechts gerichtete Kreise verübelten ihm doch seinen „Geist von Potsdam“102, wenn er damit auch etwas gemeint hat, womit jeder Süddeutsche einverstanden ist. Eugen hat dann auch überall, wo er sprach, besonders in Karlsruhe, viel Anerkennung gefunden. Häufig musste er an einem Abend zweimal sprechen. Natürlich hat ihn dies sehr mitgenommen. Nebenher liefen die hässlichen Angriffe von $\mathrm{Abg}\left[\right.$ eordneten] Wider ${ }^{103}$, aus denen er sich allerdings wenig machte. Mich haben sie sehr geschlaucht.

101 Vgl. oben.

102 Vgl. oben.

103 Wilhelm Wider (1877-1965), gebürtig aus Meimsheim, evangelisch, Fabrikantensohn, 1918 Mitbegründer der württembergischen Bürgerpartei/DNVP, 1919-1920 Mitglied der Verfassungsgebenden Landesversammlung, 1920-1932 Mitglied des württembergi- 
Dann der Ausgang der Wahlen! Mit dieser starken Zunahme der Nazzi hatten wir im Süden doch nicht gerechnet ${ }^{104}$. Es kam nun Schlag auf Schlag. Für uns waren es aufregende Tage, die Eugen aber mit bewundernswerter Ruhe und Selbstbeherrschung trug. Am Montag ${ }^{105}$ hiess es im N.S. Kurier „20 Uhr Ansprache von $\mathrm{Abg}$ [eordneten] Murr ${ }^{106}$ und Mergenthaler ${ }^{107}$ auf dem Marktplatz. Bolz muss weg!" Handzettel des gleichen Inhalts wurden verteilt. Ich war weg, und erfuhr es unterwegs in der Elektrischen, wo ich Herrn Herkommer ${ }^{108}$ traf, der mit mir heimging. Als ich heim kam, war Eugen weg. Er war kurz vor 7 Uhr gekommen, hatte zu Mina ${ }^{109}$ gesagt, die Nazzi wollten mit dem Fackelzug an unserer Wohnung vorbeikommen, sie solle das Kind ${ }^{110}$ ins Bett bringen, dann abdunkeln, er wolle mit mir inzwischen einen Spaziergang machen. Er wartete mein Kommen gar nicht $\mathrm{ab}$, sondern ging allein fort. Inzwischen hatte man vom Polizeipräsidium telephoniert, dass der Zug abgebogen worden sei und nicht bei uns vorbeikomme. Natürlich war ich um Eugens Ausbleiben in grosser Sorge. Von verschiedenen Seiten hatte man antelephoniert nach Eugen. Oberregierungsrat Vögele ${ }^{111}$ von

schen Landtags, 1932-1933 Mitglied des Reichstags, einer der führenden Politiker seiner Partei, der in Württemberg maßgeblich die Kooperation mit den Nationalsozialisten vorbereitete, 1933-1962 Mitglied der Leonberger Bausparkasse AG, ab 1930 auch Mitglied im Aufsichtsrat der Stuttgarter Bank AG, Mitbegründer, Gesellschafter und langjähriger Vorsitzender des Verwaltungsrats der Stuttgarter Hausverwaltungs-GmbH. Zu ihm: RABERG, Biographisches Handbuch (wie Anm.2) S. $1013 \mathrm{f}$.

104 NSDAP $42 \%$, Zentrum 16,9\%, SPD $15 \%$, KPD 9,3\%, Bauern- und Weingärtnerbund 5,4 \%, Kampffront Schwarz-Weiß-Rot 5,2 \%, CSVD 3,2 \%, DDP 2,2 \%.

105 6. März 1933.

106 Wilhelm Murr. Zu ihm vgl. Anm. 40.

107 Christian Mergenthaler. Zu ihm vgl. Anm. 99.

108 Gemeint ist ein Freund der Familie: Hans Herkommer (1887-1956), gebürtig aus Schwäbisch Gmünd, 1906-1910 Architekturstudium an der TH Stuttgart, 1911/1912 Referendariat im Hochbauamt Dresden, 1913/1914 in Schwäbisch Gmünd, Teilnahme als Soldat am Ersten Weltkrieg, ab 1919 selbständiger Architekt in Stuttgart, nach 1945 zusammen mit seinem Sohn Jörg. Herkommer machte sich vor allem als Architekt des katholischen Kirchenbaus einen Namen. Zu ihm: Werner Hegemann, Hans Herkommer (Neue Werkkunst), Berlin/Leipzig 1929; Matthias Schirren (Hg.), Moderne Architektur exemplarisch. Hans Herkommer (1887-1956), Kaiserslautern 2010.

109 Es handelt sich um Wilhelmine Pauline Hoeneß (1876- ca. 1936), genannt „Mina“, vierte Tochter aus der ersten Ehe des Ulmer Hoteliers Johann Georg Hoeneß (1842-1915), Stiefschwester von Maria Bolz. Sie führte zunächst Eugen Bolz, ab 1920 dem Ehepaar Bolz in Stuttgart den Haushalt. Freundliche Auskunft von Eugen Rupf-Bolz (Ulm).

110 Gemeint ist Tochter Mechthild Bolz. Zu ihr vgl. Anm. 55.

111 Oberregierungsrat Josef Vögele (1893-1974), gebürtig aus Zaisenhausen, katholisch, Besuch der Universität, Ausbildung im Pressewesen, 1912-1919 Redakteur der „Oberschwäbischen Volkszeitung“ in Ravensburg, 1919-1920 politischer Redakteur des „Schwäbischen Volksboten“ in Ulm, von daher vermutlich näher mit Maria Bolz bekannt, 1920 Leiter der Pressestelle des württembergischen Staatsministeriums (unter Blos, Hieber, Bazille und Bolz) in Stuttgart, zuletzt als Oberregierungsrat, von den Nationalsozialisten aufgrund seiner politischen Einstellung (Zentrum) im März 1933 aus dem Staatsdienst ent- 
der Pressestelle meinte, es sei schon etwas leichtsinnig, allein wegzugehen. Gegen 1/2 10 Uhr kam dann Eugen zurück. In der Stadt war überall Ruhe. Nur die S. A. suchten nach Unruhe. Mittags um 5 Uhr sprach Landtagspräsident Mergenthaler vom Balkon des Landtags aus und hisste das Hakenkreuz auf dem Landtag. Zur selben Zeit war Ministersitzung im Innenministerium, bei der beschlossen wurde, das Hakenkreuz kurz hissen zu lassen, um Blutvergiessen zu vermeiden. Nach der Sitzung blieb Bazille ${ }^{112}$ noch kurze Zeit bei Eugen. Da kamen auch schon v[on] Jagow $^{113}$, Abg[eordneter] Maier ${ }^{114}$, um die Fahne zu hissen. Eugen empfing sie

lassen, Eintritt als Direktor in die Schwabenverlag AG Stuttgart, der Gleichschaltung des katholischen „Deutschen Volksblatts“ kam er durch Einstellung der Zeitung zuvor. Zu ihm: Art. Vögele, in: Bruno Jahn, Die deutschsprachige Presse. Ein biographisch-bibliographisches Handbuch, Bd. 1, München 2005, S. 1095.

112 Wilhelm Bazille (1874-1934), gebürtig aus Esslingen, evangelisch, 1892-1896 Studium der Rechts- und Staatswissenschaften in Tübingen und München, Gerichtsreferendar beim Oberamtsgericht Geislingen und bei der Regierung des Donaukreises in Ulm, 1899-1900 stellvertretender Amtmann beim Oberamt Mergentheim, 1902-1910 Amtmann bei der Stadtdirektion Stuttgart, 1903 Studienurlaub (Mathematik und Medizin), 1910 Mitarbeiter bei der Zentralstelle für Gewerbe und Handel, 1911 Regierungsrat, seit 1913 Vorsitzender des Ortsausschusses der DP in Stuttgart, 1914-1918 Präsident der deutschen Zivilverwaltung der belgischen Provinz Limburg, 1919/1920 Mitglied der Verfassungsgebenden Landesversammlung, 1920 Regierungsrat beim Landesgewerbeamt in Stuttgart, 1920-1932 Mitglied des Landtags, 1920-1930 auch Mitglied des Reichstags, Vorstandsmitglied der Bürgerpartei/DNVP, 1930 nach innerparteilichen Streit um den Kurs der Partei Austritt, 1924-1928 Staatspräsident von Württemberg, zugleich Staatsminister des Ministeriums für Kirche und Schule (bis 1933) und seit 1926 Minister für Wirtschaft, 1924-1933 württembergischer Bevollmächtigter zum Reichsrat, 1927 Promotion zum Doktor med. h.c. in Tübingen. Raberg, Biografisches Handbuch (wie Anm. 2) S. $40 \mathrm{f}$.

113 Dietrich von Jagow (1892-1945), gebürtig aus Frankfurt/Oder, 1912 Eintritt in die Marine, Offizierslaufbahn, 1920 verweigerte er den Eid auf die Weimarer Verfassung, aus dem aktiven Dienst ausgeschieden, 1919 Mitglied der „Brigade Ehrhardt“ und Teilnahme am Kapp-Putsch, 1920 Mitglied der NSDAP und der SA, 1922 von Hitler als Instrukteur der NS-Bewegung und Inspekteur der württembergischen SA nach Tübingen geschickt, 1927 Beitritt zum Stahlhelm und zum Bund der Frontsoldaten, 1929/1930 Ortsgruppenleiter der NSDAP in Esslingen und Gaugeschäftsführer in Württemberg, 1931 hauptamtlicher SA-Gruppenführer „Südwest“, ab Mai 1932 Mitglied des Reichstags, als Reichskommissar für die württembergische Polizei Errichtung eines Konzentrationslagers auf dem Heuberg, ab 1. April 1933 Führer der SA-Obergruppe V in Frankfurt a.M., September 1933 Preußischer Staatsrat, 1934 in Berlin und Mitglied des Volksgerichtshofs, 1939-1941 als Seeoffizier Teilnahme am 2. Weltkrieg, 1941 deutscher Gesandter in Ungarn, 1944 Rückkehr nach Berlin, Führer eines Volkssturmbataillons, Anfang 1945 schwer verwundet, bei Kriegsende NS-Kurier in Südtirol, Selbstmord. Zu ihm: Heinz-Ludger Borgert, Art. Jagow, in: Württembergische Biographien 1 (2006) Sp.118-121; Barbara Hachmann, Der „Degen“. Dietrich von Jagow, SA-Obergruppenführer, in: Kissener/Scholtyseck, Die Führer (wie Anm. 40) S.267-287.

114 Karl Otto Maier (1901-1934), gebürtig aus Stuttgart, evangelisch, nach der Oberrealschule in Stuttgart Praktikant im Elektromaschinenbau, 1920-1923 Studium der Elektrotechnik an der TH Stuttgart, 1923-1928 Berechnungsingenieur in der Maschinenfabrik Esslingen, Werk Cannstatt, 1928-1930 Versuchsingenieur bei den Siemens-Werken, 
ruhig, man stellte sich vor, doch bot Eugen ihnen keinen Platz an. Bazille war auch dabei. Eugen sagte, er wolle ihnen keine Schwierigkeiten bereiten, und fragte wie lange die Fahne auf dem Ministerium bleiben solle. Sie meinten 24 Stunden. Eugen sagte, sie sollen ihm diese Verdemütigung ersparen, er werde sie nach einer Stunde einziehen lassen. Sie erwiderten nichts. Offenbar waren sie durch Eugens Ruhe etwas eingeschüchtert. Eugen sagte ihnen auch noch, die w[ür]tt[em]b[ergische] Regierung sähe ein, dass eine Änderung erfolgen müsse und sie werde keine Schwierigkeit machen, doch müsse es auf legalem Wege geschehen. Die Abg[eordneten] erwiderten, dass sie dafür keine Befugnisse hätten. Vorher hatten sie schon im Rundfunk die Flagge gehisst, wobei es 4 Verwundete gab. Nun gingen sie zu den anderen Ministerien und anderen öffentlichen Gebäuden. Alles vollzog sich in Ruhe. In der Stadt schwirrten die tollsten Gerüchte. Vom Volksblatt ${ }^{115}$ frage man an, ob ein Überfall auf unser Haus stattgefunden habe. Oberregierungsrat Vögele sagte mir, er sei mindestens $20 \mathrm{Mal}$ angerufen worden, ob es wahr sei, dass Eugen verhaftet sei. Ihr könnt Euch denken, dass ich froh war, als Eugen heim kam. Unser Haus ist übrigens schon seit 14 Tagen von 2 Polizisten bewacht. Wir wurden auch nicht belästigt. Am Dienstag ${ }^{116}$ Abend kamen ein Hauptmann und 15 Mann als Schutz, da zu befürchten [war], dass sie nach dem Hissen des Hakenkreuzes uns noch einen Besuch abstatten wollten. Es ging aber alles in Ruhe vorbei.

Am Mittwoch ${ }^{117}$ wurde dann die Stellungnahme der Regierung wie auch der Partei veröffentlicht. Um 17 Uhr war Parteisitzung, und nach dieser hatte Eugen eine Besprechung mit dem Fürsten von Wolfegg Zeil ${ }^{118}$ und Herrn Gerlich ${ }^{119}$, dem

1930-1932 Assistent an der TH Stuttgart, Mitglied der NSDAP, Juli 1930 Ortsgruppenleiter, seit 1932 Kreisleiter der NSDAP Stuttgart, Gauinspekteur und Leiter des Personalamts für den Gau Württemberg-Hohenzollern, 1932-1933 Mitglied des württembergischen Landtags, 1933-1934 (Selbstmord) auch Mitglied des Reichstags. Zu ihm: Raberg, Biographisches Handbuch (wie Anm.2) S. $537 \mathrm{f}$.

115 Gemeint ist das in Stuttgart erscheinende „Deutsche Volksblatt“, die wichtigste katholische Tageszeitung in Württemberg, gegründet 1848 durch den Theologen Florian Rieß (1823-1882), der später in den Jesuitenorden eintrat. 1875 kam es zur Errichtung einer Aktiengesellschaft „Deutsches Volksblatt“.

116 7. März 1933.

117 8. März 1933.

118 Hier irrt Maria Bolz. Es handelte sich um: Erich Fürst von Waldburg zu Zeil und Trauchburg (1899-1953), gebürtig aus Stuttgart, katholisch, Studium der Forst- und Volkswirtschaft in Tübingen und Freiburg, ab 1918 Familienoberhaupt und Übernahme der Verwaltung des Familienbesitzes, auch Teilhaber der oberschwäbischen Papierindustrie, 1926 Heirat mit Maria Monika Prinzessin zu Löwenstein-Wertheim-Rosenberg (1905-1992), 1930 Gründer der Zeitschrift „Illustrierter Sonntag“ (später: „Der gerade Weg“), Mitglied des Zentralkomitees der deutschen Katholiken, auch nach 1945 als Verleger tätig. Zu ihm: Jürgen Klöckler, Art. Waldburg-Zeil und Trauchburg, Maria Erich August Wunibald Joseph Reinhard, in: Baden-Württembergische Biographien 3 (2002) Sp. 433-434.

119 Fritz Gerlich (1883-1934), gebürtig aus Stettin, evangelisch-reformiert, 1902 Studium der Mathematik und Physik in Leipzig, 1903 der Geschichte und Anthropologie in München, 1907 historische Promotion zum Dr. phil., im bayerischen Staatsarchivdienst, publi- 
Herausgeber des Geraden Weges ${ }^{120}$. Er erhielt Informationen über die S. A ${ }^{121}$. Die Unterredung wurde unterbrochen durch die Nachricht von der Ernennung des

zistisch tätig, 1920-1928 Chefredakteur der „Münchener Neuesten Nachrichten“, allmählich innere Wandlung vom Sympathisanten zum scharfen Kritiker der nationalsozialistischen Bewegung, u.a. bestärkt durch die Bekanntschaft mit der Mystikerin Therese Neumann von Konnersreuth und deren Kreis, 1929 wieder im Archivdienst, 1930 Herausgeber der Zeitschrift „Illustrierter Sonntag“, die ab 1932 unter dem Titel „Der gerade Weg“ erschien, am 9. März 1933 in den Redaktionsräumen von einem SA-Trupp misshandelt, 16 Monate „Schutzhaft“ in München, im Zusammenhang mit dem Röhm-Putsch (30. Juni/1. Juli 1934) von der Münchner Polizeidirektion ins KZ Dachau verlegt und dort ermordet. Zu ihm: Rudolf Morsey (Bearb.), Fritz Gerlich - ein Publizist gegen Hitler. Briefe und Akten 1930-1934 (Veröffentlichungen der Kommission für Zeitgeschichte, Reihe A, Bd.56), Paderborn u. a. 2010, insbesondere S. 17-38.

${ }_{120}$ Die Zeitschrift „Der gerade Weg“ erschien von 14. Dezember 1932 bis zu ihrem Verbot durch Himmler am 13. März 1933 zweimal wöchentlich. Mit „geradezu prophetischer Voraussicht“ warnte Gerlich darin unermüdlich „vor der Gefahr der zerstörerischen Ideologie des Totalitarismus, des nationalsozialistischen wie des bolschewistischen“, und griff „dabei unentwegt auch Hitler und seinen Führerkreis direkt und massiv“ an. Morsey, Fritz Gerlich (wie Anm.119) S.7.

121 Gerlich, Waldburg-Zeil und Georg Bell, ein Nachrichtenhändler, legten Bolz eine Reihe hochbrisanter Dokumente vor, die dieser dem Reichspräsidenten zur Kenntnis bringen sollte, um hinsichtlich der bevorstehenden Gleichschaltung der süddeutschen Länder die Macht nicht in die Hände der SA, sondern der Reichswehr gelangen zu lassen. Bei den Unterlagen handelte es sich - nach der Erinnerung Waldburg-Zeils - um folgende Originaldokumente: 1. Einen Vertrag der NSDAP mit dem englisch-holländischen Petroleummagnaten Detering über die Finanzierung der SA in den Jahren vor der Machtergreifung. Als Gegenleistung sollten Deterings Ölinteressen nach der Machtergreifung bevorzugt berücksichtigt werden. 2. Die Nennung von Kronzeugen für den Mord an Hitlers Nichte Angela Raubal (†1931). 3. Die Pläne für die Vernichtung der Kirchen und deren propagandistische Vorbereitung. 4. Unterlagen zum Reichstagsbrand. 5. Unterlagen über die Absicht Röhms, Hitler nach der Machtergreifung zu beseitigen und die Macht selbst zu übernehmen. Vgl. Morsey, Fritz Gerlich (wie Anm.119) S.10 f., 36, 341. - Waldburg-Zeil hielt die Ereignisse 1941 aus der Erinnerung heraus schriftlich und nicht ohne polemische, aber ungerechtfertigte Seitenhiebe gegen Bolz fest: „Nachdem an den Reichspräsidenten nicht heranzukommen war, blieb nur noch eine Hoffnung, das war die, ein amtierendes Staatsoberhaupt in Bewegung zu bringen, dessen Besuch der Reichspräsident nicht wohl ablehnen konnte. [...] Die Idee, der bayerische Ministerpräsident solle nach Berlin fahren, wurde [in dessen Umgebung] für Wahnsinn gehalten. [...] Da ich sah, daß hier Hopfen und Malz verloren sei, versuchte ich es mit dem württembergischen Staatspräsidenten Dr. Bolz. Ich traf ihn noch am Wahlsonntag, den 5. [März] in Weingarten und sprach mit ihm über die Gefahr. Er forderte Unterlagen für meine Behauptungen und ich versprach, sie ihm zu bringen. [...] Am Mittwoch [8. März 1933] fuhr ich mit Gerlich und Bell über Zeil nach Stuttgart. Der Umweg war angebracht, da wir uns schon verfolgt und beobachtet wußten. Von Zeil aus rief ich Staatspräsident [Bolz] an, dessen traurige Stimme sagte auf meine Ansage: ,I glaub, 's isch scho alles umsonscht. Bei uns hängt'd Hakekreuzfahn aus'm Ministerium.' Ich: ,Sind Sie noch Staatspräsident?‘ Er: ,Ja, bis Dienstag.‘ Ich: ,Dann komme ich um X Uhr.' Er: ,Gut, Durchlaucht, aber [n]it ins Ministerium, sondern ins Vinzenzhaus, $\mathrm{m}[\mathrm{i}]$ habet die Parteifunktionäre zusamme g'rufe. ' So kamen wir denn eben recht zur Funktionärsversammlung. Diese Versammlung der württembergischen Parteifunktionäre der Zentrumspartei werde 
Polizeikommissars v[on] Jagow ${ }^{122}$. Sofort kam Eugen heim. An sämtliche Minister ${ }^{123}$ wurde telephoniert und sie zu einer Besprechung auf Donnerstag 9 Uhr eingeladen. Ebenso rief Eugen den Gesandten Bosler ${ }^{124}$ in Berlin an und beauftragte ihn, am Donnerstag in aller Frühe ins Reichsinnenministerium zu gehen und zu fragen, warum in $\mathrm{W}[\ddot{\mathrm{ur}}] \mathrm{tt}[\mathrm{em}] \mathrm{b}[\mathrm{er}] \mathrm{g}$, wo überall Ruhe herrsche, ein Polizeikommissar eingesetzt werde. Gegen 22 Uhr läutete es wieder an. Ich ging ans Telephon. „Abg[eordneter] v[on] Jagow. Ist Herr Staatspräsident zu sprechen?" Schnell verständigte ich Eugen. Nun hörte ich wie v[on] Jagow ein Telegramm vorlas. Mit

ich nie vergessen. Das ganze geistige Elend dieser Institution stank noch einmal auf. [...] Unmittelbar darauf begannen die Verhandlungen mit dem Staatspräsidenten, um ihn mit dem Material nach Berlin zu bringen. Er erkannte voll die Wichtigkeit und die Bedeutung des Materials. [...] Er war aber von dem Komplex besessen, sein Land in diesen schweren Stunden nicht verlassen zu dürfen. Vergebens machte ich ihm klar oder versuchte ich wenigstens, daß die Entscheidung über das Schicksal des Reiches in diesen Stunden in Berlin falle und daß die Pflichten in Württemberg bereits bedeutungslos seien, wichtig sei jetzt nur, ob die SA oder ob die Wehrmacht mit der Polizeigewalt im Reiche betraut werde; in letzterem Falle sei noch nicht alles verloren, ob Württemberg bleibe oder nicht, spiele jetzt gar keine Rolle. Er wies verzweifelt seinen Terminkalender vor, da stand nun leider klar verzeichnet, daß der arme Mann zwei Tage darauf in Friedrichshafen einen Bahnhof einweihen mußte und um dieses historische Friedrichshafener-Hafenbahnhofes willen ist die Reise auch richtig unterblieben. Wer weiß auch, ob sie Sinn gehabt hätte. Nochmals machte ich einen Versuch am Donnerstag [9. März 1933] Morgen, den Staatspräsidenten umzustimmen. Der Justizminister [Beyerle] war zugegen, aber es war nichts mehr zu erreichen“. Abgedruckt ebd., S. 335-337. - Schon am 30. Juli 1932 hatte Waldburg-Zeil im Zusammenhang mit der Gleichschaltung Preußens Bolz aufgesucht. Sein damaliger Kommentar: „Hatte gestern eine Unterredung mit dem Staatspräsidenten, bei der ich bedauerlicherweise feststellen mußte, daß sich die süddeutschen Ministerpräsidenten bei der Stuttgarter Besprechung von Papen haben vollkommen einwickeln lassen. Der Standpunkt, daß es nicht genügt, sich von jemandem, der schon andere Zusagen gebrochen hat, Zusagen geben zu lassen, daß ein Rechtsbruch nicht wiederholt wird, ist dem Staatspräsidenten leider fremd; ich glaube, es wird hier etwas unternommen werden müssen, um das Bewußtsein der Gefahr wachzuhalten“. Sonst war er eher zugeknöpft und wenig aus ihm herauszubringen“. 30 . Juli 1932 Waldburg Zeil, Schloß Zeil, an Gerlich. Abgedruckt ebd., S. $218 \mathrm{f}$.

122 Jagow war am selben Tag zum Reichspolizeikommissar ernannt worden.

123 Ressortchefs im Kabinett Bolz waren - neben Ministerpräsident Bolz (Zentrum), der auch das Innenministerium leitete - Josef Beyerle (Zentrum) für Justiz, Wilhelm Bazille (DNVP) für Kultus, Alfred Dehlinger (DNVP) für Finanzen, Reinhold Maier (DDP) für Wirtschaft. Außerdem gehörte dem Kabinett auch Johannes Rath (DVP) als Staatsrat an.

124 Otto Bosler (1872-1950), gebürtig aus Stuttgart, 1895 Eintritt in den württembergischen Justiz- und Verwaltungsdienst, 1896 Promotion zum Dr. jur., 1912 Ministerialrat im Finanzministerium, 1924-1934 stimmführender stellvertretender Bevollmächtigter Württembergs zum Reichsrat (Staatsrat), 1914-1918 Kriegsgerichtsrat, dann Ministerialdirektor im Finanzministerium, 1919 Präsident einer Abteilung beim Landesfinanzamt Württemberg in Stuttgart, 1924-1934 württembergischer Gesandter bei der Reichsregierung, 1924-1931 auch Gesandter bei der preußischen und sächsischen Staatsregierung. Zu ihm: http://www.bundesarchiv.de/aktenreichskanzlei/1919-1933/1a1/adr/adrag/kap1_2/ para2_244.html (Zugriff am 22. Oktober 2015). 
grosser Bestimmtheit sagte Eugen: „Ich ersuche Sie wenigstens bis morgen zu warten. Um 9 Uhr habe ich die Minister zusammengebeten und wir beabsichtigen uns auch an Hindenburg ${ }^{125}$ zu wenden. Da ich die schweren politischen Auswirkungen erkenne, kann ich nicht ohne weiteres zustimmen." V[on] Jagow sagte etwas, worauf Eugen „Sie kennen meine Ansicht. Tun Sie, was Sie für nötig halten.“ Bald nachher läutete Ministerialdirektor Scholl ${ }^{126}$ an. Offenbar traute ihm Eugen nicht mehr ${ }^{127}$, denn er sagte ihm ziemlich schroff: „Sie haben sich ganz passiv zu verhalten und nur meine Anordnungen auszuführen. Herr Polizeipräsident Klaiber ${ }^{128}$ kann tun, was er für richtig hält.“ In der ganzen Nacht tat Eugen kein Auge zu. Morgens war er wirklich gedrückt. Er sagte nur „Das Bitterste in diesen Tagen ist, dass man das Vertrauen in seine nächste Umgebung verliert.“ Das ging vor allem auf Scholl und Klaiber. Das Nähere weiß ich auch nicht. In der Ministersitzung

125 Paul von Hindenburg (1847-1934), gebürtig aus Posen, evangelisch, Sohn eines Offiziers, 1879 Heirat, Eintritt in die militärische Laufbahn, 1865 Leibpage der preußischen Königin Elisabeth, 1866 Teilnahme an der Schlacht von Königgrätz, und 1870/1871 am Deutsch-Französischen Krieg, 1890 Leiter der II. Abteilung im Kriegsministerium, 1900 Generalleutnant, 1911 Ruhestand, 1914 Oberbefehlshaber der 8. Armee, im November 1914 Generalfeldmarschall, 1916 Chef des Generalstabes des Feldheeres, seit 1914 enge Zusammenarbeit mit Ludendorff, die siegreiche „Schlacht bei Tannenberg“ begründete seinen politischen Mythos, 1919 Rücktritt, Urheber oder Beförderer der „Dolchstoßlegende“, 1925 Reichspräsident auf Vorschlag der Rechtsparteien, durch die Auflösung des Reichstags im Juni 1930 beförderte er die politische Instabilität und Radikalisierung. Am 30. Januar 1933 berief Hindenburg Hitler zum Reichskanzler, löste am 1. Februar 1933 den Reichstag auf und setzte durch Verordnungen die Grundrechte „bis auf Weiteres“ außer Kraft. Zu ihm: Wolfram PyтA, Hindenburg. Herrschaft zwischen Hohenzollern und Hitler, München 2009; Bernhard WiEN, Weichensteller und Totengräber. Ludendorff, von Hindenburg und Hitler 1914-1937, Norderstedt 2014.

126 Reinhold Scholl (1873-1950), gebürtig aus Langenburg, evangelisch, Jurastudium in Tübingen, 1905 stellvertretender Amtsrichter in Balingen und Stuttgart-Stadt, 1909 Expeditor im Staatsministerium, 1913 als Hilfsarbeiter abgeordnet zum Innenministerium, 1913 Amtmann in Biberach, 1914 Assessor im Innenministerium, 1918 Oberamtmann in Rottenburg, 1919 Regierungsrat und Vorstand der Polizeiabteilung im Innenministerium, 1920-1924 auf Antrag aus dem Staatsdienst entlassen, 1925 Wiedereintritt, Kanzleidirektor, 1929-1934 zweiter Ministerialdirektor und Stellvertreter des Innenministers. Scholl blieb 1933 im Amt, auch wenn er „de facto kaltgestellt und Ende 1934 in Pension geschickt“ wurde (Ruck). Das hier vorgelegte Dokument zeigt offenbar eher, dass sich Scholl mit den neuen Machthabern zunächst arrangierte. 1934-1940 Sachbearbeiter und stellvertretender Abteilungsleiter im Deutschen Auslandsinstitut Stuttgart, 1940 Eintritt in die NSDAP, 1941 Präsident in der Rechtsabteilung des Innenministeriums, 1945 Entlassung. Zu ihm: Michael Ruck, Korpsgeist und Staatsbewußtsein. Beamte im deutschen Südwesten 1928-1972 (Nationalsozialismus und Nachkriegszeit in Südwestdeutschland, Bd. 4), München 1996, S.42, 48, 100; Michael Ruck, Art. Scholl, in: Wolfram Angerbauer (Red.), Die Amtsvorsteher der Oberämter, Bezirksämter und Landratsämter in Baden- Württemberg 1810 bis 1972, hg. von der Arbeitsgemeinschaft der Kreisarchive beim Landkreistag Baden-Württemberg, Stuttgart 1996, S. $510 \mathrm{f}$.

127 Über Scholls langjährige Bekanntschaft mit Mußgay vgl. Anm.159.

128 Rudolf Klaiber. Zu ihm vgl. Anm. 9. 
wurde ein Telegramm an Hindenburg aufgegeben, ebenso Einspruch beim Reichsgerichtshof erhoben und vom Landtagspräsidenten verlangt, spätestens bis Dienstag den Landtag einzuberufen. Wir haben doch eine geschäftsführende Regierung und diese muss die Geschäfte bis zur Wahl des Staatspräsidenten weiter führen. An diesem Tage fürchtete ich eine Schutzhaft für Eugen. Von massgebender Stelle wurde ich gefragt, welchen Vertreter ${ }^{129}$ ich für Eugen nehmen werde. Eugen wurde wieder ruhig und damit auch ich. Ich wunderte mich, wie ruhig ich war. Aber ich habe ein starkes Gottvertrauen, und bin überzeugt, dass wenn auch schwere Zeiten für uns kommen werden, wir auch die Kraft zum Ertragen erhalten werden. In all den Tagen haben wir viele liebe und anerkennende Schreiben erhalten, nicht nur von Parteifreunden, sondern auch von Persönlichkeiten anderer Richtung. Im grossen Ganzen stand man aber doch allein da. Es liegt dies etwas an Eugen, der niemand um sich sehen wollte. Am zugänglichsten ist er noch zu Herkommer. Auch Direktor Pirrung ${ }^{130}$ war mal da. Die Verwandten ${ }^{131}$ liessen sich gestern und vorgestern auch blicken. Schliesslich muss dies alles allein abgemacht werden.

Am Samstag ${ }^{132}$ Vormittag verabschiedete sich Eugen von seinen Beamten ${ }^{133}$. Er dankte ihnen, wies sie aber auch auf die kommenden schweren Zeiten hin. Man-

129 Gemeint ist: welchen juristischen Beistand.

130 Adolf Pirrung (1878-1965), gebürtig aus Boxbach (Pfalz), katholisch, Maschinenbauund Elektrotechnikstudium an der TH München und der TH Berlin, zunächst bei den städtischen Elektrizitätswerken München und der Baugesellschaft für technische Anlagen in Augsburg, 1904 Heirat, 1908 als Projektingenieur der Stuttgarter Firma Reisser für rund 50 Elektrizitätswerke im süddeutschen Raum zuständig, unter anderem Aufbau einer Zweigniederlassung in Ulm, 1919 im Vorstand der Reisser-Elektrizitäts-Versorgungs-AG, 1924 bei den Oberschwäbischen Elektrizitätswerken (Vorstand: Franz Schenk Freiherr von Stauffenberg), Landesvorsitzender und stellvertretender Reichsvorsitzender der Handelsund Industriebeiräte der Zentrumspartei, persönlich mit Bolz befreundet, im April 1933 als Gegner des Nationalsozialismus nach einer diffamierenden Pressekampagne in Schutzhaft genommen. Der geplanten Einlieferung ins KZ Heuberg entging er nur durch Intervention eines Freundes. Danach von seinen Aufgaben beurlaubt, Übersiedelung nach Berlin, dort privater Sachverständiger für Energiewirtschaft und Wasserkraftnutzung, 1945 Beauftragter für die Energiewirtschaft in der französischen Besatzungszone, Generaldirektor und Vorstandsvorsitzender der Energie- Versorgung Schwaben AG, 1946 Gründungsmitglied der CDU im Landkreis Biberach, 1953 Ruhestand, 1956 von Kardinal Nicola Canali zum Ritter im Ritterorden vom Heiligen Grab zu Jerusalem ernannt. Zu ihm: Jürgen Grsın, Art. Pirrung, in: Baden-Württembergische Biographien 2 (1999) Sp. 352-355.

131 Gemeint sind wohl die Familien Leibinger (Arzt) und Mühleisen (Notar und Rechtsanwalt), Sohn und Schwiegersohn der ältesten Schwester von Bolz. Freundliche Auskunft von Herrn Eugen Rupf-Bolz (Ulm).

132 11. März 1933.

133 „Beim Abschied vom Innenministerium, das Bolz nahezu 10 Jahre geleitet, und vom Staatsministerium, dem er fünf Jahre vorgestanden hatte, erinnerte Bolz daran, daß seine Amtstätigkeit in die Zeit der Inflation, dann einer Scheinblüte und zuletzt eines offensichtlichen Niedergangs gefallen sei und daß seine Entschließungen durch diese Zeitverhältnisse weitgehend beeinflußt worden seien; insbesondere die letzte Entwicklung habe die äußerste 
chen Beamten so besonders Ministerialdirektor Held ${ }^{134}$ fiel es sehr schwer. Eugen war schon froh, seiner Stellung enthoben zu sein, als im letzten Augenblick der Landtag abgesagt wurde. Neue Erregung, neue Befürchtung einer Schutzhaft. Nicht aus Sicherheitsgründen konnte der Landtag nicht stattfinden, sondern weil es Unstimmigkeiten gab zwischen S. A. und den Nazzis. Abg[eordnete] Murr und Mergentaler hatten sich schon auf ihre Posten gefreut, aber andere wollten auch etwas werden. Den Hauptgrund sieht Eugen wohl darin, dass sie auf den Einheitsstaat zusteuern, und keine Länderregierungen wollen. Dann fürchtet Eugen, dass Polen unsere innere Schwäche ausnützen wird.

Wegen des Nichtzustandekommens des Landtages war heute wieder Ministersitzung, die Minister beschlossen, ordnungsgemäss ihre Geschäfte aufzunehmen. Nur Bazille, der die Lage noch weit ernster ansieht als Eugen, bat Eugen, ihn krankheitshalber zu beurlauben. Ich wäre froh, wenn Eugen erst [mal] weg wäre. In 8 Tagen wird Eugen in Berlin sein. Ich hätte es gern, wenn er dann einige Wochen zur Erholung fortginge, aber er will nichts davon wissen. Nun will ich meinen langen Bericht schliessen. Hoffentlich kann ich Euch bald bessere Nachricht geben.

\section{Die Festnahme von Eugen Bolz im Zusammenhang mit dem 20. Juli 1944 (August 1944)}

Die Nachrichten über die Umstände der Festnabme von Bolz im Gefolge des 20. Juli 1944 sind spärlich. Bolz wurde nicht unmittelbar nach dem gescheiterten Attentat verhaftet, sondern erst am 12. August; er hatte es abgelehnt, ins Ausland

Sparsamkeit zur Pflicht gemacht, eine schwere und bittere Aufgabe, über die er das Urteil einer späteren Zeit überlasse. Dem Dank an die Beamten und dem Lob auf das Berufsbeamtentum fügte er die Bitte an, auch in der kommenden Übergangsperiode, unabhängig von der politischen Einstellung, die Pflicht zu tun und dadurch dem Land zu nützen“. Miller, Eugen Bolz (wie Anm.3) S. 440f.

${ }_{134}$ Ministerialdirektor Dr. Robert Held (1875-1938), gebürtig aus Heilbronn, katholisch, Sohn eines Finanzrats, 1895 Studium der Rechts- und Staatswissenschaften in Tübingen, 1902 Eintritt in die württembergische Innenverwaltung, Amtmann beim Oberamt Heilbronn, 1904 Assessor beim Stadtschultheißenamt Stuttgart, 1904 Promotion mit einer Arbeit über „Das württembergische Notverordnungsrecht unter Vergleich mit dem Notverordnungsrecht anderer deutscher Staaten“, 1908 Assessor im Innenministerium, 1911 Oberamtsvorstand in Besigheim, 1918 Ministerialrat zunächst im Innenministerium, dann im Ernährungsministerium, 1927-1933 Ministerialdirektor im Innenministerium, 1933 von den Nationalsozialisten als Präsident zum Verwaltungsgerichtshof abgeschoben, um so dem späteren Innenminister Jonathan Schmid Platz zu machen, seit 1935 aufgrund eines schweren Verkehrsunfalls dienstunfähig, 1936 in den Ruhestand versetzt. Vgl. RucK, Korpsgeist (wie Anm.126) S.42 (die Vermutung Rucks, zwischen Bolz und Held habe eine gewisse Distanz bestanden, weil Held keiner katholischen Verbindung angehörte, wird durch das hier vorgelegte Dokument nicht gestützt), S.100; Michael Ruck, Art. Held, in: AngerBauer, Die Amtsvorsteher (wie Anm. 126) S.310f. 
zu gehen. Die Gestapo verbrachte Bolz zunächst ins Untersuchungsgefängnis beim Amtsgericht Stuttgart. Dort befanden sich auch schon andere Vertraute Goerdelers, so Baurat Albrecht Fischer (1877-1965) ${ }^{135}$ und Rechtsanwalt Frank. Fischer, der vom Volksgerichtshof freigesprochen werden sollte, verfasste später einen Erlebnisbericht, der in der Bolz-Historiographie, soweit ich sebe, nicht zur Kenntnis genommen wurde ${ }^{136}$. Max Miller stützte sich bei seiner Darstellung zwar auch auf eines der Dokumente, die im Folgenden abgedruckt werden ${ }^{137}$, doch geben diese selbst näheren Aufschluss. Freilich kann kaum überprüft werden, inwieweit sie den Hergang wabrheitsgemäß wiedergeben. Teile der Schilderung klingen phantastisch und konstruiert; deutlich erkennbar ist auch das Bemühen des Verfassers, sich selbst als Gutmensch zu zeichnen, der sein Möglichstes für das Freikommen von Inkriminierten tat.

Der Bericht insinuiert ein dreistufiges Verfabren. Die Stuttgarter Verhaftung von Bolz ging angeblich nicht auf Aussagen von Mitangeklagten bzw. Miteingeweibten zurück, sondern auf „einen gewissen Grossmann "138, der als Lockvogel der Gestapo fungierte, Bolz nach dem 20. Juli immer wieder besuchte und sich durch angebliche Grüße von Altkanzler Joseph Wirth (1879-1956) ${ }^{139}$ aus dem Schweizer Exil einge-

135 Gebürtig aus Stuttgart, Studium der Chemie an der TH Stuttgart, anschließend Baurat im Stuttgarter Gewerbeaufsichtsamt, 1919 Geschäftsführer des Verbandes Württembergischer Metallindustrieller, später Geschäftsführer der Vereinigung Württembergischer Arbeitgeberverbände, Mitglied der DVP, 1934 nach der Gleichschaltung der Arbeitgeberverbände wirtschaftspolitischer Berater der Robert Bosch $\mathrm{GmbH}$, von Goerdeler in die Pläne für einen Staatsstreich gegen das nationalsozialistische Regime eingeweiht, nach dem 20. Juli 1944 von der Gestapo verhaftet und Anfang August 1944 nach Berlin verbracht, am 12. Januar 1945 vom Vorwurf des Hochverrats freigesprochen, aber weiter in Haft, zuletzt im KZ Sachsenhausen, 1945 von den französischen Besatzungsbehörden in Stuttgart in verschiedenen sozialpolitischen Funktionen verwendet. Zu ihm: Klaus Eisele, Mitverschwörer des 20. Juli 1944 im deutschen Südwesten; biographische Skizzen, in: Eisele/Kunze, Mitverschwörer - Mitgestalter (wie Anm. 69) S. 129-170, hier S.142-144.

136 Albrecht Fischer, Erlebnisse vom 20. Juli 1944 bis 8. April 1945, in: Otto Kopp (Hg.), Widerstand und Erneuerung. Neue Berichte und Dokumente vom inneren Kampf gegen das Hitler-Regime, Stuttgart 1966, S.122-166.

137 Die schillernde Gestalt des Verfassers, Wilhelm Rauschenberger, dessen Entnazifizierungsverfahren noch schwebte, als Miller seine Bolz-Biographie verfasste, dürfte ein Grund dafür gewesen sein, dass das Dokument nicht in Gänze bekannt gemacht wurde.

138 Grossmann wird auch von Fischer, Erlebnisse (wie Anm. 136) S. 154 genannt. Unter denen, die wie Fischer nach seinem Freispruch vor dem Volksgerichtshof ins KZ Sachsenhausen verfrachtet wurden, war auch „ein Richard Großmann, der als Spitzel der Gestapo angesehen wurde“.

139 Gebürtig aus Freiburg, katholisch, Studium der Sozialökonomie und Mathematik in Freiburg, 1906 Promotion mit einer mathematischen Doktorarbeit, 1908 Professor am Realgymnasium Freiburg, 1909 Mitbegründer des sozial tätigen Vinzenzvereins, Eintritt in die Zentrumspartei, 1913 Mitglied der Badischen Ständeversammlung, 1914 Reichstagsmitglied, im Ersten Weltkrieg für das Rote Kreuz als Krankenpfleger tätig, 1918 badischer Finanzminister, dann Reichsfinanzminister, 1921-1922 zweimal Reichskanzler. Bekannt wurde sein Ausruf 1922 der „Feind steht rechts!“, als die Zentrumspartei 1925 erstmals eine 
führt hatte. Der Vorwurf, der gegen Bolz erhoben worden sei, habe auf Umgang mit Kommunisten gelautet ${ }^{140}$. Dieses erste Verfabren sei in Stuttgart niedergeschlagen worden. Die Freilassung habe dann aber die allgemeine Verbaftung ehemaliger Zentrumsfübrer verbindert. Und schließlich sei Bolz wegen Verstrickung in das Attentat vom 20. Juli nach Berlin überführt worden. Tatsächlich hatte Bolz - nach Miller - vom Stuttgarter Gefängnispfarrer (und dieser wiederum aus der Zeitung) erfahren, dass Goerdeler verbaftet worden war, und damit jede Hoffnung anf Freilassung verloren. Aufgrund der "Kaltenbrunner-Protokolle“ wissen wir heute, dass jedenfalls zwei Tage nach der Festnabme von Bolz, vermutlich aber wesentlich früher, den Verfolgungsbehörden eine Ministerliste vorlag, die seinen Namen enthielt ${ }^{141}$. Am 27. August wurde Bolz dann nach Berlin verlegt.

Über den Verfasser der folgenden Dokumente, Kriminalkommissar Wilhelm Rauschenberger $(* 1900)^{142}$, der die Festnahme von Bolz vorzunebmen hatte, ist in

Koalition mit der DNVP einging, trat Wirth aus der Reichstagsfraktion aus, später Reichminister für die besetzten Gebiete, unter Brüning 1930/1931 Innenminister, im März 1933 votierte er leidenschaftlich gegen das Ermächtigungsgesetz, Emigration in die Schweiz, Kontakte nach Frankreich, Großbritannien und in die USA, Vorträge in Harvard, wo er sich auch mit Brüning traf, 1935-1939 in Paris, danach wieder in der Schweiz, Versuche, eine offizielle Stellungnahme des Vatikans gegen den Antisemitismus zu erreichen, Kontakte zum „Solf-Kreis“ und „Kreisauer Kreis“, 1949 Rückkehr nach Freiburg, Gegner einer reinen Westintegration, weitgehend isoliert. Zu ihm: Ulrike Hörster-PHILIPPs, Joseph Wirth 1879-1956. Eine politische Biographie (Veröffentlichungen der Kommission für Zeitgeschichte, Reihe B, Bd. 82), Paderborn u. a. 1998; Rudolf Morsey, Leben und Überleben im Exil. Am Beispiel von Joseph Wirth, Ludwig Kaas und Heinrich Brüning, in: Paulus GorDAN (Hg.), Um der Freiheit willen. Eine Festgabe für und von Johannes und Karin Schauff, Pfullingen 1983, S. 86-117; Ulrich SchuIE, Altreichskanzler Joseph Wirth im Luzerner Exil (1939-1948), in: Exilforschung 15 (1997) S. 180-199.

140 Es bleibt fraglich, ob dies stimmt oder ob es sich hier um eine nachträgliche Konstruktion Rauschenbergers handelt. Nach Auskunft von Fischer, Erlebnisse (wie Anm. 136) S.132 wurde diesem wenige Tage nach seiner Verhaftung - die aufgrund seiner Bekanntschaft mit Goerdeler kurz nach dem Attentat erfolgte - eine lange Liste mit Namen vorgelegt, zu denen er sich äußern musste. „Bei Bolz sagte ich, ich würde ihn selbstverständlich kennen, da ich früher oft dienstlich mit ihm zu tun gehabt hätte, daß aber darüber hinaus kein Verkehr gesellschaftlicher Art bestanden habe“. Dies steht in einer gewissen Spannung zu der demonstrativen Naivität Rauschenbergers, der die Verhaftung von Bolz nicht (ausdrücklich) mit dem 20. Juli zusammenbringt. Fischer und Bolz hatten übrigens am Karlsgymnasium zusammen ihr Abitur gemacht.

141 Jacobsen, „Spiegelbild einer Verschwörung“ (wie Anm. 75) S. 210.

142 Gebürtig aus Haiterbach (Calw), evangelisch, früh Halbweise, durch Armut gekennzeichnete Jugend, nach dem Besuch der Volksschule 1914 Sattler- und Tapeziererlehrling in Nagold, 1918-1919 Ausbildung zum Feldrekruten in Belgien, 1921 Eintritt in die staatliche Ordnungspolizei, auf dem Heuberg, in Böblingen, in Schwäbisch Gmünd und Stuttgart, 1923 Unterwachtmeister, 1926 Polizeiwachtmeister beim Polizeipräsidium Stuttgart, 1930 zur Kriminalpolizei in Stuttgart abgeordnet (Abteilungen Diebstahl, Betrug, Unterschlagung), 1932 Besuch des Kriminalkommissarlehrgangs in Stuttgart, in den Jahren 1930, 1931 und 1932 wiederholt für einige Wochen oder Monate zur politischen Polizei abgeordnet, im März 1933 krank und dienstunfähig (Darmleiden), danach „ohne jegliche Befragung und 
der Historiographie wenig bekannt ${ }^{143}$. Aufschluss über ibn gibt jedoch neben einer dünnen Personalakte ${ }^{144}$ auch ein dicker Entnazifizierungsakt ${ }^{145}$. Demnach wurde Rauschenberger am 11. Mai 1945 von der Kriminalpolizei, wo er sich freiwillig meldete, aufgrund seiner Zugehörigkeit zur Gestapo festgenommen. Bereits zuvor, am 9. Mai, hatte er einen ausfübrlichen Lebenslauf vorgelegt, in dem er insbesondere seine Tätigkeit beschrieb und sich um einen positiven Eindruck bemübte. So habe er „während der ganzen Tätigkeit bei der Gestapo die Gefangenen anständig und menschlich behandelt" und nie "Gefangene misshandelt oder geschlagen". Seit einigen Jabren sei er „von einem unbändigen Hass gegen alles, was Gestapo und SS heißt, und auch Partei hieß, eingenommen“. Aus dieser Einstellung heraus habe er die Gefangenen stets „anständig und menschlich behandelt"146. Als Zengen für eine "gerechte, objektive und menschliche Behandlung " fübrte er unter anderem an: „Familie des Herrn Doktor Eugen Bolz, ehemaliger Staatspräsident. Hatte Vernebmungen im August 1944. Habe über die Anordnung der Leitung weg zablreiche Sprecherlaubnis erteilt, jede Erleichterung gewährt. Waren des Lobes über mich

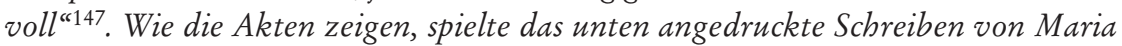
Bolz im Verfabren jedoch keine Rolle. Im Zuge der Ermittlungen traten nach dem Krieg vielmehr etliche Kläger bzw. Zeugen auf, die Rauschenberger eine besondere Brutalität vorwarfen, insgesamt ein erdrückendes Material ${ }^{148}$. Wäbrend die Ver-

gegen meinen Willen von 1 Stunde zur anderen zur neugebildeten politischen Polizei im ehemaligen Hotel Silber in Stuttgart, Dorotheenstraße 2-4, abgeordnet“, 1933 Eintritt in die NSDAP, bei der Gestapo in der Hauptsache mit Vernehmungen und Ermittlungen in Fällen illegaler Arbeit der aufgelösten Parteien und Organisationen der Opposition und Linkspartei beauftragt. „Bei Vorschlägen zur Entlassung Festgenommener, bei der Bearbeitung von Gnadensachen, die ich in vielen Fällen hatte, wurde meine menschliche Einstellung und das Bestreben, die milderen Bestimmungen anzuwenden, in den meisten Fällen durchkreuzt und mir vielfach vorgehalten, ich sei zu weich, ich müsse härter, noch härter usw. werden“. 1942 Kriegseinsatz im Osten (Russland), im April 1945 von der Gestapo Stuttgart nach Nürtingen abgeordnet. 9. Mai 1945 Lebenslauf Rauschenbergers. Entnazifizierungsakte. StAL EL 903/1 Bü 314.

143 Ernst KleE, Das Personenlexikon zum Dritten Reich. Wer war was vor und nach 1945?, Frankfurt a. M. 2003 erwähnt Rauschenberger nicht. Dagegen aber: BAUZ/BrüGGEMann/Maier (wie Anm. 159) S. 53, $169 \mathrm{f}$.

144 StAL EL 51/1 I.

145 StAL EL 903/1 Bü 314. - Vgl. auch einige Duplikate in der Handakte des öffentlichen Klägers: StAL EL 905/4 Bü 2604.

146 23. Mai 1945 Rauschenberger, Stuttgart, an den Chef der deutschen Polizei der Stadt Stuttgart. StAL EL 903/1 Bü 314.

147 9. Mai 1945 Lebenslauf Rauschenbergers. Entnazifizierungsakte. StAL EL 903/1 Bü 314 .

148 Die Zwiespältigkeit kommt zum Ausdruck in einem Schreiben des öffentlichen Klägers Cremers vom 14. Juli 1947 an die Ermittlungsabteilung: „Rauschenberger wird als gefährlicher und gehässiger Gestapobeamter geschildert, der stellenweise unter dem Deckmantel der Loyalität, im Grund genommen jedoch unnachsichtig und brutal war. Bitte um genaue Ermittlung“. StAL EL 903/1 Bü 314. 
teidigung die Einstufung als Mitläufer beantragte ${ }^{149}$, wurde Rauschenberger am 4. Dezember 1947 als „Hauptschuldiger" zu fünf Jabren Arbeitslager und Einziehung des Vermögens verurteilt ${ }^{150}$. Gegen diesen Spruch legte Rauschenberger Berufung ein und stellte den Antrag, unter anderem auch Maria Bolz als Zeugin zu laden. Sie sollte bekunden, „dass ich entgegen bestehender Anordnungen versucht habe, ibren Mann am 23.8.1944 auf freien Fuß zu setzen, außerdem durch Gewährung von wiederholten Besuchen, Zulassung von Lebensmitteln usw. nicht nur meine innerste Teilnabme bekundet, sondern in all diesen Dingen gegen meine Dienstpflichten gehandelt babe". Auch Justizminister Beyerle sollte geladen werden, „der bekunden wird, dass ich Ibn, trotz strikten Auftrages, ihn ins Gefängnis einzulagern, dies nicht tat, sondern ihn auf mein Amtszimmer verbrachte und nach langwierigen Verhandlungen mit dem Amtsleiter seine Freilassung erwirkte und dass ich mich auch ihm gegenüber als ehemaligen führenden Starts-Zentrumsführer äußerst korrekt und zuvorkommend behandelt habe"151. Durch Spruch vom 21. September 1948 wurde Rauschenberger allerdings wiederum in die Gruppe der Hauptschuldigen eingereibt. Auch gegen diesen Spruch legte Rauschenberger Berufung ein. Aufgrund einer sebr umfangreichen Beweisaufnabme wurde schließlich das ursprüngliche Urteil modifiziert ${ }^{152}$.

149 Der Verteidiger vermutete, dass die belastenden Angaben auf Verwechslung beruhten. Außerdem sah er die Entlastungszeugen nicht angemessen gewürdigt. Bei seiner Auflistung der Entlastungszeugen wurde zwar Justizminister Beyerle genannt, der Fall Bolz fehlte jedoch. 30. Oktober 1947 Rechtsanwalt Wiedmann, Stuttgart, an Spruchkammer des Internierungslagers 72. - „Zu seiner Entlastung während seiner Tätigkeit als Gestapo-Beamter macht der Betroffene geltend, dass er ab September 1944 ca. 440 Angehörige vor der Sippenhaft bewahrt hat. Ferner behauptet er, aus der A-Kartei, wonach bei Kriegsbeginn politisch unzuverlässige Leute hätten verhaftet werden sollten, mehrere 100 Personen herausgenommen zu haben. Er gab ferner an, dass er mehr als die Hälfte der Personen, die im Verdacht standen, mit dem Attentat vom 20. Juli in Verbindung zu stehen, aus einer Liste gestrichen habe. Weiter habe er die Widerstandsgruppe Breuninger nicht verfolgt, ebenso Gechter, Binder usw. Die Wahrheit seiner Angaben konnte die Kammer nicht überprüfen, es wird jedoch in diesem Zusammenhange auf die Akten seines Dienstvorgesetzten Kohler verwiesen“. 4. Dezember 1947 Spruch der Spruchkammer Internierungslager Ludwigsburg. StAL EL 903/1 Bü 314.

150 Ebd.

151 5. September 1948 Rauschenberger, Ludwigsburg, an Spruchkammer der Internierungslager. StAL EL 903/1 Bü 314.

${ }^{152}$ Dabei wurde neben der Vielzahl von Fällen tatsächlicher Misshandlungen auch der Tatsache Rechnung getragen, dass Rauschenberger in einer ganzen Reihe von Fällen sich der vom Nationalsozialismus Verfolgten in fürsorglicher Weise angenommen hatte. Die Kammer war der Überzeugung, „dass der Betreffende in seiner Behandlung der von ihm zu vernehmenden Personen weit über das Maß dessen hinausgegangen ist, was zu den Obliegenheiten eines Untersuchungsbeamten gehört, dass er Mittel und Methoden angewendet hat, die verabscheuenswert sind“. Aber auch, dass der Betroffene „tatsächlich im bewussten Gegensatz zu seinen Amtspflichten durch teilweise Vernichtung der einschlägigen Kartei erreicht“ hatte, „dass politisch unzuverlässige Personen nicht ins KZ kamen“. Entgegen 
Wilhelm Rauschenberger an Maria Bolz, 15. Mai 1947

Handschriftlicher Brief, 2 Seiten.

HStAS Q 1/25 Bü 24.

Himmelfahrtstag, 15.5. [19]47

Sehr verehrte Frau Dr. Bolz!

Ich bitte höfl[ich] um Entschuldigung, wenn ich mir von hier aus erlaube, Ihre Zeit mit diesen Zeilen in Anspruch zu nehmen. Ich habe auf der Verwaltung erfahren, daß Sie versucht haben, mich hier zu sprechen. Aus welchem Grunde dies nicht erfolgen konnte, kam mir nicht zur Kenntnis. Vor allem möchte ich Ihnen, verehrte Frau Dr. Bolz, für das für mich in liebenswürdigerweise gefertigte Entlastungszeugnis ${ }^{153}$ herzlichst danken. Den 11.5.[19]47 waren es 2 lange Jahre, die ich hinter Draht u[nd] Zaun verbracht habe. Ich weiß, es ist gegenüber Ihnen u[nd] dem Leid Ihrer $1[\mathrm{ie}] \mathrm{b}$ [en] Tochter ungleich geringere Last, aber es sind eben doch über 730 Tage und Nächte, die nicht immer angenehm waren. In all der Zeit habe ich oftmals an Sie u[nd] das herbe Los Ihres hochgeschätzten Mannes denken müssen. Ich war, als ich damals vom plötzlichen Abtransport Ihres 1[ie]b[en] seligen Gatten hörte - ich war ja schwerkrank infolge gehabten Fleckfiebers 1942 - tief erschüttert u[nd] „empört“. Fr[äu]l[ein] Berner ${ }^{154}$, sie ist auch tot, hatte es mir unter Tränen mitgeteilt. Und dann hörte ich erst im April vom schrecklichen Urteil gegen Ihren 1[ie]b[en] Mann. Sehr geehrte Frau Bolz! Wenn ich Ihnen heute von hier aus, wie schon damals, ehrenwörtlich versichere, daß weder ich, noch Herr Inspektor Kohler ${ }^{155}$, irgendetwas gewußt haben, das an eine Schuld Ihres Mannes

der ihm gegebenen Weisung habe er weitere Leute vor der Durchführung von Verfahren bewahrt, Gnadengesuche für Verfolgte verfasst und belastendes Material aus den Untersuchungsakten beseitigt. Die Berufungsinstanz kam deshalb zu einer milderen Einstufung. 16. November 1949 Spruch der Zentralberufungskammer Nord-Württemberg. - Ein Gnadengesuch wurde am 18. Januar 1954 vom Gnadenausschuss abgelehnt. StAL EL 903/1 Bü 314.

153 Unten abgedruckt.

154 Hedwig (Emma) Berner (1903 - ca. 1945), gebürtig aus Stuttgart, 1923 Schreibgehilfin, Antrag auf Reisepass, spätestens 1930 Kanzleiassistentin. StAL F 215 Bü 356; F 215 Bü 3.

155 Johann Kohler (*1899) gebürtig aus Talheim Kreis Tuttlingen, evangelisch, 1906-1913 Besuch der evangelischen Volksschule Schramberg, 1913-1915 der Fortbildungsschule Schramberg, 1917-1918 Teilnahme am Weltkrieg, 1921 Eintritt in die württembergische Schutzpolizei, 1928 Polizeiwachtmeister im Polizeipräsidium Stuttgart, bis 1933 SPDWähler, 1933 Mitglied des Kameradschaftsbundes deutscher Polizeibeamten, 1934-1935 Unterstützer der Allgemeinen SS, 1934 Oberwachtmeister, 1936-1945 Mitglied der Nationalsozialistischen Volkswohlfahrt (NSV), 1937 Hauptwachtmeister, 1939-1940 Waffenwart, 1940-1942 im Elsass, 1942-1943 in Russland, April 1943 bis Juni 1943 in Marseille, im März 1945 Entlassung aus dem Dienst. „Ich wurde als einer der ersten zu einem Polizeibataillon abgeordnet. [...] 1940 wurde jede Beförderung von Himmler abgelehnt, weil ich mit einer Nichtariern verheiratet bin“. 18. Mai 1946 Fragebogen des Military Government of Germany. StAL EL 902/20 Bü 9932. Auch: Bauz/Brüggemann/Maier (wie Anm. 159) S. 168. 
über die damalige haltlose Anzeige hinaus auch nur denken ließ, so dürfen Sie dieses Wort getrost glauben. Ich habe als kleiner Mann der Staatspolizei alles getan, um Ihrem 1[ie]b[en] Mann zur Freiheit zu verhelfen. Ich wußte gar bald, daß jener Grossmann, der anscheinend für eine Stelle arbeitete $u[n d]$ dann auch in Haft genommen wurde, ein gemeiner Spitzel $u[n d]$ der Urheber der Anzeige gegen Ihren Mann selbst, wenigstens mittelbar, war. Deshalb habe ich auch sofort bei Erkenntnis dieses Umstandes alle Verdächtigungen als Denunziation aufgefaßt, den Worten Ihres 1[ie]b[en] Mannes geglaubt u[nd] durchgesetzt, daß er am 23. 8. [19]44 entlassen werden sollte. Leider kam dann die unwürdige Haft gegen ehemalige Zentrumsführer, die eine andere Dienststelle durchführte $u[n d]$ dann dieser 27. 8. [19]44, der Abtransport nach Berlin.

Verehrte Frau Dr. Bolz! Wenn ich in über 2 Jahren Haft schon manchmal bereut habe, in vielen vielen Fällen ebenso unmenschlich gehandelt zu haben, weil trotzdem $\mathrm{Haß} \mathrm{u}[\mathrm{nd}]$ Rache vorherrschen, so ist es mir doch stets eine innere Befriedigung, daß gerade ich es sein durfte, der Ihren von mir stets hochverehrten seeligen Mann u[nd] Ihnen das Los, so gut es ging, etwas erleichtern konnte. Daß ich Herrn Minister Dr. Beyerle ${ }^{156}$ die Haft ersparen konnte, ist auch heute noch meine besondere Genugtuung ${ }^{157}$. Ich sollte Herrn Dr. Beyerle ja gleich ins Gefängnis führen.

156 Josef Beyerle. Zu ihm vgl. Anm. 32 .

157 Beyerle äußerte sich darüber nach dem Krieg folgendermaßen, was die Ausführungen Rauschenbergers nicht in jedem Fall bestätigt: „Wilhelm Rauschenberger, früher Kriminalsekretär in Stuttgart, hat bei mir um eine Aeusserung bitten lassen über sein Verhalten bei meiner Festnahme im August 1944. Ich kann hiezu Folgendes angeben: Rauschenberger erschien an jenem Tage morgens kurz nach 6 Uhr. Er vollzog seinen Auftrag in durchaus rücksichtsvoller Weise. Als ich nach Verbringung auf das Polizeipräsidium erklärte, dass ich an diesem Tage eine Verhandlung des ersten Zivilsenats des Oberlandesgerichts zu leiten hatte, und deswegen Massnahmen einzuleiten sein werden, erklärte er mir, dass dies ein neuer Umstand sei, der eine Nachprüfung des Festnahmebefehls notwendig mache. Man sei bisher davon ausgegangen, dass ich ohne amtliche Tätigkeit im Ruhestand sei. Er nahm sofort ein Protokoll hierüber auf, suchte und fand Verbindung mit dem stellvertretenden Leiter seiner Dienststelle. Das Ergebnis war, dass ich nach etwa 2 Stunden wieder auf freien Fuss gesetzt wurde. Da ich Rauschenberger vorher in keiner Weise gekannt habe, habe ich sein Verhalten als menschlich rücksichtsvoll empfunden. Ueber seine sonstige Dienstführung ist mir nichts bekannt. (gez.) Beyerle“. 6. März 1947 Justizminister (Beyerle), Gutachten (Abschrift). StAL EL 903/1 Bü 314. - Nach der Verlesung dieser Stellungnahme äußerte sich Rauschenberger in der Verhandlung vom 4. Dezember 1947: „Zu dieser Aktion wurden einzelne Beamte von uns hinzugezogen. Ich bekam von Schurr den Haftbefehl. Ich hatte damals schon die Ansicht, dass dies ein Unrecht sei. Ich wartete vor der Türe, bis sich Herr $\mathrm{B}$ [eyerle] angezogen hatte. Als ich ihm meinen Namen nannte, sagte er, dass er schon einmal mit der Polizei zu tun hatte und ich mich damals gut benommen hätte. Ich sollte ihn ins Gefängnis bringen, ging jedoch nicht dorthin, sondern zu Herrn Kohler. Ich habe mich dort mit dem Oberregierungsrat in Verbindung gesetzt wegen der Freilassung von B[eyerle]. Überall wurde ich abgewiesen, so habe ich den Herrn B[eyerle] auf meine eigene Verantwortung hin auf freien Fuß gesetzt“". Aus dem Verhandlungsprotokoll vom 4. Dezember 1947. StAL EL 903/1 Bü 314. 
Falls Sie, verehrte Frau Dr. Bolz, über jene Dinge, die zur ersten Festnahme Ihres 1[ie]b[en] Mannes geführt haben, eingehender von mir geschildert haben möchten, wäre ich dazu gerne schriftlich oder mündlich bereit. Ein Gesuch um Sprecherlaubnis an den Herrn Lagervorstand König persönlich hätte sicherlich Erfolg.

Mit nochmaligem herzlichen Dank für Ihr Zeugnis grüßt Sie, Ihre Tochter ${ }^{158}$ $\mathrm{u}$ [nd] Herrn Dr. Beyerle, dem ich meinen Dank ebenfalls auszusprechen bitte, recht herzlich

Wilhelm Rauschenberger, Nr. 2157

Intern[ierungs] Lager 72 - Bau 5/5

14 a Ludwigsburg.

Wilbelm Rauschenberger an Maria Bolz, Juni 1947

Handschriftlicher Bericht, 7 Seiten.

HStAS Q 1/25 Bü 24.

Intern[ierungs] Lager 72

Im Juni 1947

Betreff: Festnahme des ehemaligen württembergischen Staatspräsidenten Herrn Dr. Eugen Bolz.

Am 12. August 1944, ein Samstag, bekam das Sachgebiet IV 1 a der Staatspolizeihilfsstelle Stuttgart, den ich als Berufsbeamter (Krim[inal] Sekretär) angehört habe, Bereitschaftsdienst, $\mathrm{d}[\mathrm{as}] \mathrm{h}[\mathrm{eißt}]$, es durfte von den 4-5 Beamten keiner das Amt verlassen.

Ich selbst wurde gegen 10 Uhr vormittags zu dem damaligen Leiter des Amtes, $\mathrm{Ob}$ [er] Regier[ungs]- u[nd] Krim[inal] Rat Mussgay ${ }^{159}$ befohlen. Ich war krank gemeldet, mußte aber trotzdem, da ich einige Stunden arbeiten mußte, dem Befehl Folge leisten.

158 Mechthild Bolz. Zu ihr vgl. Anm. 55.

159 Paul Emil Friedrich Mußgay (1892-1946), gebürtig aus Ludwigsburg, Sohn eines Hausmeisters, Besuch der Verwaltungsfachschule in Stuttgart, wo er Reinhold Scholl (vgl. Anm.126) kennenlernte, mit dem er auch später noch Kontakt hatte, 1914-1918 zeitweilig Teilnahme am Weltkrieg, Verwaltungsassistent in Esslingen, Ellwangen und Mergentheim, 1917 Eintritt in die Polizeidirektion Stuttgart, 1920 Verwaltungssekretär, 1921 Polizeikommissar in der Dienststelle 3 (Nachrichtendienst, Vereins- und Versammlungswesen) der Abteilung II b der Politischen Polizei, von Kollegen als „Kommunistenjäger“ bezeichnet, 1932 Polizeirat, 1933 Eintritt in die NSDAP, die SS, Wechsel in das neugestaltete Politische Landespolizeiamt, Leiter das Referats N (Nachrichtendienst), 1935 Kriminalrat, 1937 Leiter der Abteilung 2 (Verfolgung der Gegner des NS-Regimes durch Dokumentation, Vernehmung von Verhafteten durch Drohungen und andere Zwangsmaßnahmen), 1938 auch im SD und SD-Hauptamt eingesetzt, Versetzung nach Brünn, Ende 1939-Mai 1940 möglicherweise stellvertretender Leiter der Staatspolizeileitstelle Kattowitz, 1940 stellvertretender Leiter 
In Gegenwart des Leiters des Nachrichtendienstes des Amtes, einem Krim[inal] Inspektor ${ }^{160}$, erhielt ich den Auftrag, Herrn Dr. Eugen Bolz in Stuttgart, sowie einen gewissen „Grossmann“, - er hatte ein Büro in der Schlandstraße, festzunehmen.

Auf meinen Einwand, daß ich krank gemeldet sei u[nd] mir eine aufregende Arbeit am besten nicht übertragen werde, wurde mir von Mussgay bedeutet, daß es mir nicht zustehe, mich einer Aufgabe zu entziehen, die in mein Referat, also das des Hochverrats, falle.

Auf meine erstaunte Frage, seit wann denn Herr Dr. Bolz, der mir doch als Zentrumsmann bekannt sei, zu den „Kommunisten“, die ich ausschließlich zu bearbeiten habe, gehöre, erklärte mir Mussgay in zynischer Weise: Sie erhalten die nötigen und gesammelten Beweise sofort ausgehändigt. Das Material enthält genügend Beweise, daß Dr. Bolz mit Kommunisten Verbindung aufgenommen u[nd] sich auch über das mißglückte Attentat vom 20.7.1944 ${ }^{161}$ sehr gefährlich geäußert hat.

Außerdem erklärte mir Mussgay, daß ich selbst deshalb den Auftrag durchzuführen habe, weil ich der einzig verfügbare $u[n d]$ geeignete Beamte sei. Dies war natürlich eine glatte Lüge. Vielleicht auch nahm er an, es schmeichle mir, diese „Auszeichnung“ zu hören. (Nebenbei: Was konnte mir schon imponieren, nachdem mich diese „Herren“ durch ein nie verdientes „Alkoholverbot“, Beförderungssperre usw. zum Beamten u[nd] Menschen 2. Klasse gestempelt hatten?)

der Staatspolizeileitstelle Stuttgart, ab Juli 1941 deren Leiter, u. a. für die Hinrichtung von Polen und NS-Gegnern sowie für die Deportation von etwa 2.600 Juden verantwortlich, nach seiner Flucht im April oder Mai 1945 verhaftet und ins Militärgefängnis von Stuttgart verbracht, 1946 Selbstmord. Zu ihm: Friedrich Wilhelm, Die Württembergische Polizei im Dritten Reich, Stuttgart 1989, S.405-443; Roland MaIER, Friedrich Mußgay. GestapoChef und Organisator der Juden-Deportationen, in: Hermann G. AвмAYr (Hg.), Stuttgarter NS-Täter. Vom Mitläufer bis zum Massenmörder, Stuttgart 2009, S.120-125; Jürgen Schuhladen-Krämer, Die Exekutoren des Terrors. Hermann Mattheiß, Walther Stahlecker, Friedrich Mußgay, Leiter der geheimen Staatspolizeileitstelle Stuttgart, in: KIssEnER/ Scholtyseck, Die Führer (wie Anm.40) S.405-437; Ingrid Bauz/Sigrid Brüggemann/ Roland Maier (Hg.), Die Geheime Staatspolizei in Württemberg und Hohenzollern, Stuttgart 2013.

160 Paul Jahn (1893-1949), evangelisch, gebürtig aus Sulzgries/Esslingen, 1919 bei der Stuttgarter Kriminalpolizei, 1933 Wechsel zur Politischen Polizei (1936 in Geheime Staatspolizei, Staatspolizeileitstelle Stuttgart umbenannt), dort zuständig für Spionageabwehr, 1941 Übernahme des N-Referats (das bis 1937 Mussgay geleitet hatte), Kriminalinspektor. Wahrscheinlich zuvor Eintritt in die SS (Beitrittsgesuch 1941), 1945 Mitglied der Untergrundorganisation „Elsa“, bevor er von den Franzosen verhaftet wurde. Freundliche Auskunft von Friedemann Rincke (Haus der Geschichte Baden-Württemberg) vom 21. Oktober 2015.

161 Dazu vgl. Hans-Adolf Jacobsen, Die Opposition gegen Hitler und der Staatsstreich vom 20. Juli 1944, Seewald 1984; Rudolf LiLl, 20. Juli 1944 in Baden und Württemberg (Portraits des Widerstands, Bd.3), Konstanz 1994; Stephen Schröder, Der 20. Juli 1944 Profile, Motive, Desiderate. XX. Königswinterer Tagung 23.-25. Februar 2007 (Schriftenreihe der Forschungsgemeinschaft 20. Juli e.V., Bd. 10), Münster 2008. 
Zunächst sollte jener Grossmann festgenommen werden, wurde aber in seinem Büro, ebenso in der Wohnung nicht angetroffen. Es hieß, er sei nach Dänemark abgereist oder nach Norwegen.

Ich selbst kannte Grossmann nicht, erhielt aber über ihn die mündliche Mitteilung, daß er „V.Mann“ des S.D. sei, also Spitzel, daß er für das Amt VI in Berlin (Reichssicherheits-Hauptamt) arbeite ${ }^{162}$, vermutlich aber auch Aufträge von deutschfeindlicher Seite angenommen habe. Außerdem habe er mit Kommunisten in Stuttgart $\mathrm{u}[\mathrm{nd}] \mathrm{Möhringen} \mathrm{engere} \mathrm{Verbindung;} \mathrm{jedenfalls} \mathrm{aber} \mathrm{sei} \mathrm{seine} \mathrm{Fest-}$ nahme ebenfalls angeordnet $\mathrm{u}[\mathrm{nd}] \mathrm{zwar}$ von Berlin aus.

Nachdem letztere zunächst nicht möglich war, ordnete Mussgay persönlich die Festnahme von Herrn Dr. Bolz an. Inzwischen war es Mittag geworden. Ich selbst mußte im Amt bleiben, bis Mussgay obgenannten Befehl gab. Wahrscheinlich um meine Amtshandlung zu überwachen, gab mir Mussgay einen Mann vom S. D. mit, den ich nicht ablehnen konnte, da er scheinbar mit die Finger in diesem „Intrigenspiel“ hatte. Leider ist mir sein Name nicht bekannt.

Wenn die damalige Festnahme von Herrn Dr. Bolz streng dienstlich durchgeführt werden mußte, so war dieser S. D. Mann schuld, der drängte, so schnell als möglich zu Ende zu sein.

Er war es auch, der ein von Herrn Dr. Bolz in der Hand gehaltenes, auch von mir beobachtetes „Feindflugblatt“ blitzschnell an sich nahm, während ich es nicht sehen „wollte“. Ich habe dieses nachträglich vernichtet, um auch diesen einzigen Belastungspunkt in der „Stuttgarter“ Sache nicht anführen zu müssen.

Das Belastungs-Material gliederte sich in 3 Punkte:

1. Verbindung mit Grossmann, dieser als Verdächtiger, für das Ausland zu arbeiten.

2. Verbindung mit dem Kommunisten Binder, Richard ${ }^{163}$, Stuttgart-Münster, (den ich entkommen lassen konnte).

3. Die angeblich Grossmann gegenüber getane Äußerung: das am 20.7.1944 auf $\mathrm{A}$ [dolf] $\mathrm{H}[$ itler] verübte $\mathrm{u}[\mathrm{nd}]$ mißglückte Attentat werde in 4 Wochen mit besserem Erfolg durchgeführt. Er, Herr Dr. Bolz, habe gute Verbindungen und wisse es genau. Angefügt war in einem „Geheimbericht“, dessen Urheber mir nie bekannt wurde (vermutlich hatte Grossmann mit diesem Bericht selbst zu tun), daß Dr. Bolz mit Emigranten in der Schweiz Verbindung habe $u[n d] d a ß$ auffallend viele Geistliche verdächtigerweise bei ihm verkehren ${ }^{164}$.

162 Wurde nicht ermittelt.

163 Richard Binder (1894-1970) saß schon früher im KZ Ulm in Schutzhaft. Näheres ist nicht bekannt. Vgl. Rudolf ReNz, Württembergisches Schutzhaftlager Ulm. Ein frühes Konzentrationslager im Nationalsozialismus (1933-1935). Informationen und Arbeitshilfen für den Besuch der Ulmer KZ-Gedenkstätte mit Schülern, hg. vom Oberschulamt Tübingen, Tübingen 2004, S. 105.

164 Das war insofern nicht verwunderlich, als Bolz nicht nur kirchlich sozialisiert war, sondern in seiner Verwandtschaft auch etliche katholische Geistliche hatte. Auch Maria 
Ich habe Herrn Dr. Bolz von Anfang an für unschuldig gehalten, weil ich nicht nur als Beamter, sondern auch aus rein vernunftsmäßigen Erwägungen gefolgert habe, daß Herr Dr. Bolz, als frommer, glaubenstreuer Katholik niemals mit den Kommunisten paktieren würde. Außerdem war mir klar, daß, hätte er mit Grossmann politische, staatsfeindliche Dinge gemeinsam durchführen wollen, er nicht in so auffallend plumper Weise, wie dem als geschildert, gearbeitet hätte.

Die unter 3. angeführte Äußerung vollends traute ich Herrn Dr. Bolz schon intelligenzmäßig nie zu. So einfältig und offen hätte nur ein seiner 5 Sinne nicht Mächtiger tun können, niemals Herr Dr. Bolz.

Auf dieser meiner Überzeugung habe ich dann auch, unbeschadet der entgegenstehenden Überzeugung des Leiters Mussgay u[nd] seiner ihm zugetanen Nachrichten-Männer, die ganze Vernehmung von Herrn Dr. Bolz geführt.

Als Ergebnis wurde dann von mir kurz zusammengefaßt; festgestellt:

1. Herr Dr. Bolz hat mit Richard Binder, Münster, oder Kommunisten (Auch ${ }^{165}$ $\mathrm{u}[\mathrm{nd}]$ andere aus Möhringen) keinerlei Verbindung gehabt. Binder wurde ihm lediglich im Büro des Grossmann zufällig nur flüchtig vorgestellt. Er traf sich nie mit Binder, nie mit Auch und anderen, hatte mit ihnen nie etwas zu tun.

Dagegen hat die Vernehmung des Grossmann ergeben, daß dieser mit Binder, Auch $\mathrm{u}[\mathrm{nd}]$ anderen Verbindung aufnahm, um sie zu bespitzeln u[nd] zu verraten.

2. Die ihm zur Last gelegte oben unter 3. angeführte Äußerung hat nicht Herr Dr. Bolz, sondern Grossmann selbst Herrn Bolz gegenüber getan, im Bericht aber die Sache auf den Kopf gestellt.

3. Die Auslandsverbindungen habe ich als nicht vorhanden als Ergebnis der Feststellungen niedergelegt.

Grossmann hatte sich, als Spitzel, an Herrn Dr. Bolz herangemacht, um ihm Grüsse von Herrn Reichskanzler a.D. Wirth, Schweiz, zu übermitteln. Mehr hatte Grossmann trotz der aufgebauschten Berichte, die zweifellos er selbst verfasst hatte, mir gegenüber nicht anzugeben.

Eine zufällige Begegnung mit Dr. Goerdeler ${ }^{166}$ in Vaihingen-Filder konnte anhand des in Stuttgart vorliegenden, oben geschilderten unhaltbaren Materials keinesfalls einen strafbaren Tatbestand erfüllen.

Es stand daher am 21.8.1944 einwandfrei fest, daß Herr Dr. Bolz am 23.8.1944, nach endgültigem Abschluß der sich mir durch Abwesenheit des Grossmann (am 20.8.1944 festgenommen) verzögerten Ermittlungen auf freien Fuß gesetzt worden wäre.

Leider kam dann die Festnahme-Aktion gegen ehemal[ige] Zentrumsführer, zu denen auch Herr Dr. Bolz gezählt wurde, sodaß seine erneute Festsetzung am

Bolz war durch ihre ehrenamtliche Tätigkeit, etwa für den Caritasverband, eng in kirchliche Kreise eingebunden.

${ }^{165}$ Der hier genannte Kommunist Auch aus Möhringen konnte nicht nachgewiesen werden.

166 Carl Friedrich Goerdeler. Zu ihm vgl. Anm. 65. 
22.8.1947 durch eine andere Dienststelle angeordnet $\mathrm{u}[\mathrm{nd}]$ Herr Dr. Bolz damit mir u[nd] meinem Sachgebiet entzogen wurde.

Nachdem ich Herrn Justizminister Dr. Beyerle, den ich befehlsgemäß hätte sofort ins Gefängnis einliefern müssen, nach hartem Wortstreit dem Leiter Mussgay geradezu entrissen hatte, mußte ich mich erneut krank melden, da meine Nerven versagten, ob all dieser Ungerechtigkeiten. Ich wußte über den weiteren Verlauf der Sache nicht Bescheid, bis mir meine Schreibhilfe, Fräulein Hedwig Berner ${ }^{167}$ $(\dagger)$ nach meiner Rückkehr den plötzlichen Abtransport nach Berlin von Herrn Dr. Bolz erschüttert mitteilte.

Nach Wochen erschien dann auf der Dienststelle ein Krim[inal] Inspektor aus Berlin, der im Zusammenhang mit dem 20.7.1944 einen Jakob Weimer ${ }^{168}$, der todkrank darniederlag, abholen wollte. Wir $\mathrm{u}[\mathrm{nd}] \mathrm{die}$ Ärzte lehnten ab. Weimer starb dann auch zu Hause nach 3 Wochen ${ }^{169}$.

Dieser Inspektor nun wurde von mir $\mathrm{u}$ [nter] a[nderem] befragt, was eigentlich gegen Herrn Dr. Bolz vorliege. Ich selbst hätte ihn in anderer Sache vernommen und seine Unschuld in der Stuttgarter Sache klar und eindeutig festgestellt, weshalb auch seine Entlassung bereits angeordnet gewesen sei.

Nach längerem Zögern erklärte jener Inspektor (Name ist mir nicht bekannt, er stammte aus Südwestdeutschland $u[n d]$ war nach Berlin abgestellt), es habe schon seine Richtigkeit mit Dr. Bolz; er habe lange geleugnet, aber man habe verstanden!!! - ihn zum Reden zu bringen. Dr. Bolz habe zugegeben, daß er von gewissen Personen befragt worden, ob er im Falle eines Umschwunges einen Regierungsposten (welchen?) annehmen werde; zugestandenermaßen habe Dr. Bolz zugesagt ${ }^{170}$.

167 Hedwig Berner. Zu ihr vgl. Anm. 154.

168 Jakob Weimer (1887-1944), gebürtig aus Gültstein, Schlosser- und Mechanikerlehre, Eintritt in die SPD und Gewerkschaftsmitglied, hier v.a. ab 1920 Funktionärsaufgaben, 1921 Bezirkssekretär des Allgemeinen Deutschen Gewerkschaftsbundes für Württemberg, Hohenzollern, Baden und Pfalz (Südwest) in Stuttgart, 1927-1933 als Nachrücker für die SPD im württembergischen Landtag, im März 1933 in den letzten Reichstag der Weimarer Republik gewählt, hier Ablehnung des Ermächtigungsgesetzes, im Mai 1933 erstmalige Verhaftung, nach der Freilassung Versicherungsangestellter, im Sommer 1944 als mutmaßlicher Mitverschwörer des Attentats vom 20. Juli von der Gestapo verhaftet, zunächst aber ins Robert-Bosch-Krankenhaus eingeliefert, wo ihm Ärzte monatelang Transportunfähigkeit attestierten, im November 1944 starb er im Keller des Krankenhauses infolge brutaler Verhöre durch die Gestapo. Zu ihm: Raberg, Biographisches Handbuch (wie Anm. 2) S. 996; Kurt LeIPner, Chronik der Stadt Stuttgart 1933-1945 (Veröffentlichungen des Archivs der Stadt Stuttgart, Bd. 30), Stuttgart 1982, S. 1009.

169 Die Auskunft Rauschenbergers widerspricht den heute bekannten Angaben, Weimer sei im Keller des Krankenhauses infolge brutaler Gestapo-Verhöre verstorben.

170 Inwieweit dieses Geständnis zutrifft, lässt sich nicht sagen. Gesichert scheint hingegen, dass Bolz in Berlin nicht nur unter erschwerten Haftbedingungen litt, sondern auch gefoltert wurde. Vgl. Miller, Eugen Bolz (wie Anm. 3) S. $497 \mathrm{f}$. 
Meinen Einwand, das könne ich persönlich niemals glauben, dazu hätte ich eine ganz entgegengesetzte Meinung von Herrn Dr. Bolz erhalten, entkräftete der Inspektor mit dem Bemerken, daß wir in Stuttgart eben nichts gewußt hätten.

$\mathrm{Zu}$ weiteren Äußerungen ließ er sich nicht herbei.

Wilhelm Rauschenberger

Int[ernierungs] Lager 72, Bau 5/5.

Maria Bolz: Zengnis für Wilhelm Rauschenberger, 6. März 1947

Maschinenschriftliche Abschrift, 2 Seiten.

StAL EL 903/1 B̈̈ 314.

Frau Maria Bolz

(14 a) Stuttgart-N., 6.3. [19]47

Am Kriegsbergturm 44

Fernruf 91887

Am 12. August 1944 hat Wilhelm Rauschenberger, Kriminalsekretär bei der Staatspolizeileitstelle Stuttgart, im Auftrag der Gestapo, meinen Mann, den ehemaligen württembergischen Staatspräsidenten Dr. Eugen Bolz, verhaftet. Herr Rauschenberger, den ich zum erstenmal sah, nahm die Verhaftung streng dienstlich, jedoch korrekt vor. Zwei Tage später lehnte der Vertreter des Polizeipräsidenten Mus[s]gay meine Bitte ab, meinen Mann sprechen zu dürfen. Beim Hinausgehen aus dem Amtszimmer traf ich Herrn Rauschenberger, der mich zu einer Vernehmung in seiner Kanzlei aufforderte. Bei dieser verhielt er sich ebenfalls sehr korrekt, gebot mir aber zu Schweigen, über diese Vernehmung, besonders die Nennung eines Namens. Im Laufe der Unterredung fragte ich ihn, an wen ich mich wenden könnte, um meinen Mann sprechen zu können. Nach einiger Überlegung sagte er mir, er selbst wolle dies bewerkstelligten, und bat mich, am darauffolgenden Tag vorbeizukommen. Er hat mir dann wirklich dreimal eine Unterredung mit meinem Mann im Polizeipräsidium ermöglicht. Er selbst hat meinen Mann im Amtsgerichtsgefängnis abgeholt und zweimal durfte ich meinen Mann vom Polizeipräsidium ins Amtsgerichtsgefängnis zurückbegleiten. Dabei hatte ich Gelegenheit, weil Herr Rauschenberger uns vorausgehen ließ, wenigstens kurz mit meinem Mann allein zu sprechen. Bei den Unterredungen im Polizeipräsidium war Herr Rauschenberger immer zugegen. In meiner Anwesenheit legte er meinem Mann auch ein Protokoll vor, mit dem Hinweis, er habe für sich selbst ein solches ausgearbeitet und möchte wissen, ob mein Mann mit der Darlegung seiner Aussagen in diesem Protokoll einverstanden sei. Mein Mann erwiderte, daß es im wesentlichen mit seinen Aussagen übereinstimme. Der Inhalt dieses Protokolls ist mir leider unbekannt. $\mathrm{Zu}$ diesen Unterredungen durfte ich auch meinem Mann Lebensmittel bringen. Herr Rauschenberger hatte mich darauf aufmerksam gemacht, daß in das 
Amtsgerichtsgefängnis keine Lebensmittel gebracht werden dürften, er wolle ihm dies gerne gestatten. Noch ehe mein Mann aus dem Amtsgerichtsgefängnis wegkam, wurde Herr Rauschenberger krank, was ich sehr bedauerte, weil sein Nachfolger nicht mehr dieses Entgegenkommen zeigte. Seit dieser Zeit habe ich Herrn Rauschenberger nicht mehr gesehen und gesprochen. Ich kann also nur das Urteil abgeben, daß er meinem Mann und mir gegenüber sich menschlich verhielt.

(gez.) Frau Maria Bolz. 